\title{
Liposomes Loaded with Activatable Disulfide Bridged Photosensitizer: Towards Targeted and Effective Photodynamic Therapy on Breast Cancer Cells
}

\author{
Asiye Gok Yurttas $1,2 \mathbb{1}$, Kurtulus Gokduman ${ }^{3,4, * \mathbb{D}}$, Nezih Hekim 5 (D) \\ 1 Biorobotics and Biosensor Laboratory, Faculty of Electrical and Electronics Engineering, Istanbul Technical University, \\ Istanbul, Turkey; asiyegok@ gmail.com (A.G.Y.); \\ 2 Faculty of Pharmacy, Istanbul Health and Technology University, Istanbul, Turkey \\ 3 Institute of Biomedical Engineering, Bogazici University, Istanbul, Turkey; k.gokduman@ gmail.com (K.G.); \\ 4 Center for Engineering in Medicine, Massachusetts General Hospital, Harvard Medical School, Boston, MA, USA \\ 5 Department of Medical Biochemistry, Faculty of Medicine, Biruni University, Istanbul, Turkey; nezihhekim@ gmail.com \\ (N.H.); \\ * Correspondence: k.gokduman@gmail.com;
}

Scopus Author ID 25723120100

Received: 15.03.2021; Revised: 8.04.2021; Accepted: 10.04.2021; Published: 20.04.2021

\begin{abstract}
The motivation of the current study is to develop a strategy providing targeted and effective photodynamic therapy (PDT) on breast cancer cells by eliminating the limitations of PDT. For this purpose, a disulfide bridged phthalocyanine with favorable wavelength absorbance that is activatable in cancer cells was synthesized and encapsulated in liposome nanoparticles. The synthesized molecule was characterized using Fourier transform-infrared (FT-IR) spectroscopy, nuclear magnetic resonance (NMR) spectroscopy, Matrix-Assisted Laser Desorption/Ionization Time of Flight (MALDI-TOF) Mass Spectrometry, Ultraviolet-visible (UV-Vis) spectrophotometry, and particle size analyzer; and the nano-formulation was tested on MCF-7 breast cancer cell line using MTT assay, fluorescence microscopy, and flow cytometry. The results have illustrated that the synthesized disulfide bridged phthalocyanine has a therapeutically active wavelength absorbance value $(685 \mathrm{~nm})$, the liposome nanoparticles with the favorable characteristics (average size of $167.6 \mathrm{~nm}$ and polydispersity index (PDI) of 0.108) containing the synthesized disulfide bridged phthalocyanine have low dark toxicity, and significant light toxicity ( $\mathrm{P}<0.001$ vs. dark toxicity) characterized with significant apoptosis ( $\mathrm{p}<$ 0.05 vs. control group). Thus, for further investigations, these results suggest the great potential of the nano-formulation towards targeted and effective PDT on breast cancer cells.
\end{abstract}

Keywords: phthalocyanine; photodynamic therapy; tumor-specific activation; disulfide-bridged photosensitizer; liposome.

(c) 2021 by the authors. This article is an open-access article distributed under the terms and conditions of the Creative Commons Attribution (CC BY) license (https://creativecommons.org/licenses/by/4.0/).

\section{Introduction}

In this century, in every country of the world, cancer is expected to be the most important cause of death and the biggest obstacle to an increase in life expectancy; recently, over 10 million new cancer cases are diagnosed every year, for instance, over 18 million new cancer cases and over 9.5 million deaths from cancer have been mentioned in 2018 estimates [1-3]. In both sexes combined, with over 2 million new cases (11.6\% of total cases) and over 625,000 deaths ( $6.6 \%$ of total cancer deaths) annually, among 36 cancers, breast cancer is forecasted to be the second (behind lung cancer) and fourth (behind the lung, stomach and liver cancers) in terms of incidence and mortality, respectively, in 2018; on the other hand, breast 
cancer is the most frequently diagnosed cancer among women and is the leading cause of cancer deaths [1]. Therefore, as in other types of cancer, targeted and effective treatment strategies with minimal side effects are crucial for breast cancer. Since conventional treatment modalities have serious issues: in the case of chemotherapy, side effects like myelosuppression, mucositis, alopecia, etc.; in the case of radiotherapy or chemotherapy, recurrence of certain tumors and needs of surgery to remove the cancer cells completely; in the case of radiotherapy, needs of a precise operation to the tumor site to minimize the damage to the surrounding normal tissues; in the case of immunotherapy, the inconsistent therapeutic outcomes for different patients [2, 4-7].

Photodynamic therapy (PDT) is a rapidly developing potent modality of the clinically approved and minimally invasive alternate methods that do not require surgical intervention to treat various cancers, such as bladder, esophagus, respiratory tract, and gynecologic cancers [2, 8]. PDT is based on the combined use of a photoactivatable drug called a photosensitizer (PS), light (especially from lasers), and molecular oxygen; PS accumulates at the tumor tissues and is activated by a light source with a specific wavelength, resulting in energy transfer cascades yielding the formation of cytotoxic reactive oxygen species (ROS) (the main form of ROS produced in PDT is singlet oxygen $\left.\left({ }^{1} \mathrm{O} 2\right)\right)$ in the presence of endogenous molecular oxygen, to eventually cause cell death and vasculature damage leading to the destruction of tumor tissues [2, 8-11]. With this promising mechanism, compared to traditional cancer treatment modalities, PDT has several unique superiorities, including noninvasiveness, low toxicity, definite efficacy, and no drug resistance, which has led to the translation of this modality into clinics for the treatment of various tumors, such as bladder cancer, lung cancer, head and neck cancers, and skin cancer $[2,12]$. Also, clinical trials on other types of cancer, including breast cancer (ClinicalTrials.gov: NCT02872064) are ongoing [13]; thus, PDT is a potent modality that can be an alternative for conventional treatment modalities having serious issues for the treatment of breast cancer.

On the other hand, PDT has some limitations: I- Low selectivity of PSs including clinically approved PSs, such as porfimer sodium (Photofrin $®$ ) and meta-tetrakis(3hydroxyphenyl) chlorin (Foscan®), leading to side effects such as skin photosensitivity and damage to neighboring healthy tissue [12]; II- The limited light or PS penetration leading to difficulties in the treatment of bulky or deep-seated tumors, e.g., in the case of Photofrin ${ }^{\circledR}$, the limited penetration of the appropriate light prevents sufficient depth of tumoricidal action [13]; III- Hydrophobicity of the most effective PSs leading to low solubility and aggregates, which causes trouble for penetration into tumor tissue $[13,14]$. Therefore, to fulfill the requirements of an ideal photosensitizer as much as possible, the research on new photosensitizers with optimum properties is still ongoing [15].

In this context, the current study's motivation is to develop a strategy providing targeted and effective PDT on breast cancer cells by eliminating the above mentioned limitations of PDT. For this purpose, we aimed to synthesize a novel molecule with wavelength absorbance value within the range of $650-800 \mathrm{~nm}$, to synthesize the dimeric form of this molecule as a PS, and to encapsulate the synthesized PSs in liposome nanoparticles. According to the basic law of photobiology, the longer the wavelength of light, the deeper the light penetrates biological tissues [16]; an ideal molecule should have a strong absorption peak in the red to the nearinfrared spectral region (between 650 and $800 \mathrm{~nm}$, a therapeutic window for clinical PDT treatment, in which light can deeply penetrate the skin; to excite oxygen to its singlet state, the energy provided by absorption with wavelengths longer than $800 \mathrm{~nm}$ is not enough) $[17,18]$. 
Therefore, we aimed to synthesize the novel molecule with wavelength absorbance value within the range of 650-800 $\mathrm{nm}$. Phthalocyanines are aromatic heterocycles consisting of four isoindole rings bridged by nitrogen atoms and have many advantages in PDT applications due to their long absorption wavelength maxima $\left(\lambda_{\max }>670 \mathrm{~nm}\right)$, high extinction coefficients $\left(\varepsilon_{\max }\right.$ $>1 \times 10^{5} \mathrm{M}^{-1} \cdot \mathrm{cm}^{-1}$, two orders of magnitude higher than most porphyrins), strong absorption in the phototherapeutic window, and low or no absorption at 400-600 nm where the intensity of sunlight is the highest (this feature provides decreased levels of skin photosensitization caused by daylight) $[19,20]$. Therefore, we aimed to synthesize the novel molecule with wavelength absorbance value within the range of $650-800 \mathrm{~nm}$, which belongs to the phthalocyanine group. The photochemical properties of phthalocyanines are strongly influenced by the coordinated central metal ion; the presence of diamagnetic elements in the central cavity gives them high triplet quantum yields $\left(\Phi_{\mathrm{T}}>0.4\right)$ with long triplet lifetimes $\left(\tau_{\mathrm{T}}\right.$ $>100 \mu \mathrm{s})$ and adequate triplet energies $\left(\mathrm{E}_{\mathrm{T} 1}=1.2 \mathrm{eV}\right)$, making them efficient generators of singlet oxygen $\left(\Phi_{\Delta}>0.4\right)$; zinc(II) phthalocyanines have advantageous characteristics that allow more effective PDT, such as low dark toxicity, high chemical, and photochemical stability, high therapeutic effect (e.g., the complexing with zinc(II) increases the amount of singlet oxygen generated, causing an intensified photodynamic action), minimal skin photosensitivity and excitation at wavelengths greater than $630 \mathrm{~nm}[20,21]$. Therefore, we aimed to synthesize the novel molecule with wavelength absorbance value within the range of 650-800 nm, which belongs to the phthalocyanine group and contains zinc(II) as a diamagnetic element in its central cavity. On the other hand, despite these attractive features, as in other molecules in the phthalocyanine group, zinc(II) phthalocyanines have hydrophobic nature leading to poor solubility and aggregates through $\pi$ - $\pi$ stacking, which causes trouble for penetration into tumor tissue $[13,14,19,20]$. Since photochemical activity is exclusively associated with monomer species, aggregate formation reduces phthalocyanines' ability to produce singlet oxygen [18, 20, 22]. Herein, we aimed to bind the synthesized zinc(II) phthalocyanine monomers to each other with disulfide bonds in order to convert the aggregation handicap of phthalocyanines to cell-selective and activatable characteristics to obtain targeted and effective PDT based on the well-known mechanisms in the literature: ISimilar to the well-known effect of disulfide bond in many biological systems (e.g., the secondary and tertiary structures of many proteins contain the disulfide bond that plays an important role in the folding and stability of proteins) [23], the dimeric form formed by the disulfide bond enhances phthalocyanine aggregation, which causes self-quenching and inactivation of the synthesized phthalocyanine [24, 25]; II- It is well known that due to the differentiation of metabolic pathways in tumor cells, they have four times higher glutathione (GSH) concentration than that of normal cells [23, 26]; III- It is well known that GSH cleaves disulfide bonds; thus the cleavage of the disulfide bonds takes place selectively in tumor cells due to the GSH concentration differences between tumor and healthy cells [23-25, 27]; IV- The cleavage of the disulfide bonds results in activation of self-quenched phthalocyanine complexes with disulfide bridges selectively in tumor cells by decreasing aggregation of the phthalocyanines [24, 27]; V- After activation selectively in tumor cells, the phthalocyanine molecules absorb irradiation or light beam, transfer their energy to molecular oxygen, resulting in the production of singlet oxygen. Despite the abovementioned prominent strategies to enable targeted and effective photodynamic therapy, there is a last handicap (hydrophobicity) of the synthesized zinc(II) phthalocyanine molecules under physiological conditions to overcome. In this context, nanotechnological approaches provide promising alternatives to minimize the 
problems caused by hydrophobic molecules under physiological conditions [2, 12, 28-31]. To this end, lipid-based nanoparticles, particularly liposomes, come to the fore with their highly advantageous features such as the ability to improve the selectivity of cancer chemotherapeutic agents by passive (the Enhanced Permeability and Retention (EPR) effect) and active targeting to lower the cytotoxicity of anti-cancer agents to normal tissues, to carry neutral, hydrophilic and hydrophobic molecules, to increase the solubility of hydrophobic molecules, to enable a prolonged and controlled release of agents [29, 32, 33]. Thus, liposome nanoparticles enable a promising system of the photosensitizers' targeted delivery to the tumor tissue in PDT, which has been illustrated by previous experimental and clinical studies, e.g., the liposomal benzoporphyrin derivative monoacid (BPDMA) was approved by Switzerland and the USA [34]. Due to the mentioned superior properties of the liposome nanoparticles, the dimeric form of the synthesized zinc(II) phthalocyanine molecules has been encapsulated in liposome nanoparticles.

\section{Materials and Methods}

\subsection{Synthesis of phthalocyanines.}

Solid-phase synthesis of monofunctionalized "AB3-type" phthalocyanines was performed at $130{ }^{\circ} \mathrm{C}$ under argon atmosphere and purified by column chromatography on silica gel using dichloromethane (DCM)/ethanol. The yield of resultant monofunctionalized phthalocyanine monomers $(1771.61 \mathrm{~g} / \mathrm{mol})$ was $0.552 \mathrm{~g}(29 \%) .0 .047 \times 10^{-3} \mathrm{mmol}$ of these monomers $(81 \mathrm{mg})$ were mixed by the same moles of dicyclohexylcarbodiimide (DCC) and 1,3-Dicyclohexylcarbodiimide-4-Dimethylaminopyridine (DMAP) for two hours. After adding $0.016 \times 10^{-3} \mathrm{mmol}$ ethyl 2-hydroxyethyl sulfide, the mixture was incubated at room temperature for four days by mixing. The reaction was ended by immersing the mixture in water, and the product was purified by preparative thin-layer chromatography using DCM/ethanol. The yield of resultant functionalized dimeric disulfide derivatives (3661.54 $\mathrm{g} / \mathrm{mol})$ was $0.010 \mathrm{~g}(17 \%)$.

To prepare a dimeric reference compound, $0.016 \times 10^{-3}$ mol monofunctionalized phthalocyanine monomers (30 mg) were mixed with $3.3 \mathrm{mg}$ DCC, $0.016 \times 10^{-3}$ mol DMAP (2 $\mathrm{mg}), 0.005 \times 10^{-3} \mathrm{~mol} 1,6$-Hexandiol $(0.6 \mathrm{mg})$, and the mixture was dissolved in $6 \mathrm{ml}$ DCM for four days at room temperature. The reaction was ended by immersing the mixture in water, and the resulting product was purified by preparative thin-layer chromatography using hexane/ethanol (2:1). The yield of the resultant dimeric reference compound $(3625.48 \mathrm{~g} / \mathrm{mol})$ was $0.015 \mathrm{~g}(83 \%)$.

To prepare a monomeric reference compound, $0.008 \times 10^{-3}$ mol monofunctionalized phthalocyanine monomers $(15 \mathrm{mg})$ were mixed with $0.004 \times 10^{-3}$ mol DMAP $(10 \mathrm{mg})$ and dissolved in $0.004 \times 10^{-3} \mathrm{~mol}$ propanol $(3.1 \mu \mathrm{L})$ for four days at room temperature. The reaction was ended by immersing the mixture in water, and the resulting product was purified by preparative thin-layer chromatography using hexane/ethanol $(2: 1)$. The yield of the resultant monomeric reference compound $(1798 \mathrm{~g} / \mathrm{mol})$ was $0.008 \mathrm{~g}(57 \%)$.

\subsection{Characterization of the synthesized products.}

Various measurements were performed in triplicate to determine the suitability of synthesized disulfide-bridged dimeric phthalocyanines for PDT by Fourier transform-infrared 
(FT-IR), nuclear magnetic resonance (NMR), Matrix-Assisted Laser Desorption/Ionization Time of Flight Mass Spectrometry (MALDI-TOF), UV-visible spectra, and Zetasizer.

The resulting chemical formula of the synthesized disulfide-bridged dimeric phthalocyanine (ASG20) was C178H238N16O30S14Zn2. All measured characteristics of the synthesized ASG20 are given below:

FT-IR (v, cm $\left.{ }^{-1}\right): 2928\left(\mathrm{CH}_{2}\right), 1712(\mathrm{C}=\mathrm{O}), 1462(\mathrm{AR}-\mathrm{CH}), 1292(\mathrm{SO}), 1140(\mathrm{C}-\mathrm{O}-\mathrm{C})$, 660 (S-S). UV-visible (DMSO): $\lambda, \mathrm{nm}, 307,685$. MALDI-TOF-MS (DHB): m/z 3684 (calculated for $[\mathrm{M}+\mathrm{Na}]+, 3661.54 \mathrm{~g} / \mathrm{ml}$ ).

The resulting chemical formula of the synthesized non-cleavable dimeric phthalocyanine (REF1) was $\mathrm{C} 180 \mathrm{H} 242 \mathrm{~N} 16 \mathrm{O} 30 \mathrm{~S} 12 \mathrm{Zn} 2$, and all measured characteristics are given below:

FT-IR (v, cm $\left.{ }^{-1}\right)$ : $2927\left(\mathrm{CH}_{2}\right), 1624(\mathrm{C}=\mathrm{C}), 1569\left(\mathrm{R}-\mathrm{CH}_{3}\right), 1309$ (SO), 1242 (C-O-C). UV-visible (DMSO): $\lambda$, nm, 350, 704. MALDI-TOF-MS (TRANS): m/z 3661 (calculated for $[\mathrm{M}+\mathrm{K}]+, 3625.48 \mathrm{~g} / \mathrm{mol})$.

The resulting chemical formula of the synthesized monomeric phthalocyanine (REF2) was $\mathrm{C} 90 \mathrm{H} 122 \mathrm{~N} 8 \mathrm{O} 15 \mathrm{~S} 6 \mathrm{Zn}$, and all measured characteristics are given below:

FT-IR (v, cm $\left.{ }^{-1}\right)$ : $2927\left(\mathrm{CH}_{2}\right), 1570(\mathrm{AR}-\mathrm{CH}), 1569\left(\mathrm{R}-\mathrm{CH}_{3}\right), 1309$ (SO), 1242 (C-O-C). $1 \mathrm{H}$ NMR (CDCl3, $500 \mathrm{MHz}): \delta$, ppm $8.88(\mathrm{~s}, 2 \mathrm{H}), 8.84(\mathrm{~s}, 6 \mathrm{H}), 8.21(\mathrm{~d}, 6 \mathrm{H}), 8.11(\mathrm{~d}, 2 \mathrm{H}), 7.76$ $(\mathrm{d}, 3 \mathrm{H}), 7.28(\mathrm{~s}, 2 \mathrm{H}), 4.67(\mathrm{~s}, 3 \mathrm{H}), 4.33(\mathrm{t}, 2 \mathrm{H}), 3.23(\mathrm{~s}, 2 \mathrm{H}), 3.0(\mathrm{~d}, 6 \mathrm{H}), 2.95(\mathrm{t}, 12 \mathrm{H}), 2.75$ $(\mathrm{d}, 6 \mathrm{H}), 1.75(\mathrm{~s}, 18 \mathrm{H}), 1.5(\mathrm{~s}, 18 \mathrm{H}), 1.25$ (s, 18H), 1.0 (s, 18H). UV-visible (DMOS): $\lambda$, nm, 380, 669. MALDI-TOF-MS (DHB): m/z 1841 (calculated for $[\mathrm{M}+\mathrm{K}]+, 1798 \mathrm{~g} / \mathrm{mol}$ ).

Using the light-scattering technique, the hydrodynamic diameter size, particle size distribution, and zeta potential of the liposome nanoparticles diluted in deionized water (300 $\mu \mathrm{l}$ of liposome solution in $6 \mathrm{ml}$ of deionized water) were measured with a particle size analyzer (Malvern Mastersizer 2000 and Malvern Nano ZS90, Malvern Instruments, Malvern, UK).

\subsection{Cell Culture and maintenance.}

MCF-7 cells (Human malignant breast cancer cells) were obtained from American Type Culture Collection (ATCC, USA) and were maintained under standard culture conditions. Cells were cultured in Dulbecco's modified Eagle's medium (DMEM) supplemented with $10 \%$ fetal bovine serum (Sigma, USA) containing $1 \%$ penicillin and streptomycin (Sigma, USA).

MCF-7 cells were grown in T-25 flasks in a moisturized atmosphere maintained at 37 ${ }^{\circ} \mathrm{C}$ with $5 \% \mathrm{CO}_{2}$. When reached 70-80\% confluency, the cells were passaged using trypsinEDTA (Sigma, USA).

The number of live cells was determined by the trypan blue exclusion test. Briefly, the cell suspension is simply mixed with an equal amount of trypan blue and then visually examined to determine whether cells take up or exclude dye.

\subsection{Determination of optimal liposome concentration.}

The empty liposomes at 3, 6, 12, and $27 \mathrm{mg} / \mathrm{mL}$ concentrations in DMSO (2\% or $4 \%$ ) were analyzed by MTT assay to determine optimal liposome concentration that does not cause a significant effect on the viability of MCF-7 cells; thus, it was aimed to evaluate the effect of synthesized photosensitizers by using liposomes at the optimal concentration for encapsulation; and the liposomes of this optimal concentration were used in all of the subsequent experiments. 
MTT assay was performed by applying the liposomes in four different concentrations $(3,6,12$, and $27 \mathrm{mg} / \mathrm{mL})$ to the MCF-7 cells $\left(1 \times 10^{4}\right.$ cells/well of 96 well plate) for 24 hours. At the end of 24 hour-incubation, $10 \mu 1$ MTT was added to the cell medium and incubated for 3 hours at $37{ }^{\circ} \mathrm{C}$ to examine the effects of the liposomes on cell viability. Cell viability was measured at $540 \mathrm{~nm}$ using a spectrophotometer and then calculated according to the following formula: Viability $=($ Sample-Blank $) /($ Control-Blank). Three different experiments were carried out three times in three different weeks.

\subsection{Liposomization of the synthesized phthalocyanines.}

The liposomes were prepared according to a previous report [35]. Briefly, $3 \mathrm{mg}$ phospholipid (Lipoid S75, $78 \mathrm{~g} / \mathrm{mol}$ ) was dissolved in $470 \mu \mathrm{l}$ ethanol, and $10 \mu \mathrm{l}$ of this solution was mixed with $90 \mu \mathrm{l}$ of $2 \%$ dimethyl sulfoxide/phosphate-buffered saline ( $\mathrm{pH}: 7.4$ ) (DMSO/PBS) solution containing $1 \mathrm{mg}$ phthalocyanine (ASG20; $3661.54 \mathrm{~g} / \mathrm{mol}$ ). Liposomes were examined microscopically under $100 \mathrm{x}$ magnification. The final concentration of liposomes was $0.70 \mathrm{mM}$ (6 mg phospholipid $/ \mathrm{ml} \mathrm{EtOH})$ and phthalocyanine was $50 \mu \mathrm{M}$.

The above procedures were repeated for monomeric and dimeric reference compounds, using REF2 (1798.71 g/ mol) for the monomeric reference and REF1 $(3625.48 \mathrm{~g} / \mathrm{mol})$ for the dimeric reference, instead of ASG20. Liposomes were examined microscopically under 100x magnification.

\subsection{Photodynamic therapy.}

A dark toxicity study was conducted to determine if the synthesized phthalocyanine (ASG20) has any cytotoxic effects on MCF-7 cells in its inactive state (without any light). $1 \mathrm{x}$ $10^{4}$ cells were cultured for $24 \mathrm{~h}$ before being exposed to PSs in four different concentrations, $1,5,10$, and $20 \mu \mathrm{M}$, prepared from the main stocks of phthalocyanine liposomes, which were prepared according to the literature [36]. The culture medium was removed from each well; the cells were washed with PBS and treated with PSs. For each set of experiments, cells were divided into 5 groups as control group containing no liposomes; ASG20 group containing one of four concentration of phthalocyanine liposomes; reference 0 (REF0) containing liposomes with a commercially available unsubstituted molecule without any functional group (Sigma, CAS Number 14320-04-8, USA); reference 1 (REF1) containing liposomes with the synthesized dimeric reference unbreakable with GSH; reference 2 (REF2) containing liposomes with the synthesized monomeric reference. Each set of experiments and each concentration was tested in triplicate. The plates were wrapped in aluminum foil and incubated at a humidified temperature of $37^{\circ} \mathrm{C}$ in a $5 \% \mathrm{CO}_{2}$ incubator for $24 \mathrm{~h}$. The cells were collected for viability and flow cytometric assays.

For phototoxicity studies, the cells were first cultivated with PSs for $24 \mathrm{~h}$ and then photosensitized with an Efos LED (690 nm doses of 5, 10, $20 \mathrm{j} / \mathrm{cm} 2)$, then collected and analyzed for the cell viability and the levels of necrosis and apoptosis. Each set of experiments and each concentration was tested in triplicate.

\subsection{Cytotoxicity assay to evaluate the photodynamic therapy.}

To evaluate the photodynamic therapy MTT assay was performed using the collected cells ( 1 x $10^{4}$ cells/well of 96 well plates) after the dark and light protocols described above. $10 \mu \mathrm{l}$ MTT was added to the cell medium and incubated for 3 hours at $37{ }^{\circ} \mathrm{C}$ to examine the 
liposomes' effects on cell viability. Cell viability was measured at $540 \mathrm{~nm}$ using a spectrophotometer and calculated according to the following formula: Viability $=$ (SampleBlank) / (Control-Blank). Three different experiments were performed in triplicate in three different weeks.

\subsection{Flow cytometric assay to evaluate the photodynamic therapy.}

The effects of phthalocyanine-containing liposomes on apoptosis and necrosis of cells were determined using flow cytometric assay by staining with Annexin V / 7AAD technique. FITC conjugated Annexin V allows the staining of phosphatidylserines released in the cell membrane during activation of the apoptosis pathway, while 7AAD stains the cell nucleus representing the late stage of apoptosis and necrosis. As a result, non-stained cells are considered viable, cells stained with only Annexin V are considered as early apoptotic, cells stained with the only 7AAD are considered as necrotic, and cells stained with both are considered as late apoptotic.

Cells $\left(8 \times 10^{5}\right.$ cells/well) were seeded in 6-well plates containing $2 \mathrm{ml}$ of medium and incubated at $37^{\circ} \mathrm{C}$ for 24 hours. The determined amounts of apoptosis and necrosis at 24 hours after applying PSs and light treatment were analyzed by flow cytometry (BD Accuri ${ }^{\text {TM }}$ C6 Plus).

\subsection{Statistical analyses.}

All values were reported in descriptive statistics as mean $\pm \mathrm{SD}$. Comparison of two unpaired variables was performed by unpaired t-test with Welch correction. Comparison of more than two nonparametric variables was made by Friedman Test (Nonparametric Repeated Measures ANOVA), and Dunn's Multiple Comparisons Test was used for a post hoc test. Comparison of more than two parametric variables was made by One-way Analysis of Variance (ANOVA), and Tukey-Kramer Multiple Comparisons Test was used for a post hoc test.

For all the statistical analyses, $\mathrm{p}<0.05$ was used as the threshold for significance. Analyses were performed using Graphpad Instat (GraphPad Software, San Diego, CA, USA).

\section{Results and Discussion}

\subsection{Synthesis and characterization of the photosensitizer.}

Our designed molecules were dimeric tetrapyrroles (ASG20) (Figure 1) that increase their aggregation by binding tetrapyrol macrocycles to each other through disulfide bonds and thereby self-quench their photophysical properties [24, 25].

In this study, FT-IR, 1H-NMR, 13C-NMR, MALDI-TOF, and UV-visible spectra were used to determine the convenience of synthesized disulfide-bonded dimer for PDT. Considering the FT-IR spectra of the synthesized monofunctionalized phthalocyanine complex (Supplementary Figure S1), the peaks observed at $3080 \mathrm{~cm}^{-1}, 2930 \mathrm{~cm}^{-1}, 1738 \mathrm{~cm}^{-1}, 1462 \mathrm{~cm}^{-}$ 1, $1290 \mathrm{~cm}^{-1}$, and $1140 \mathrm{~cm}^{-1}$ represent $\mathrm{O}-\mathrm{H}$, aliphatic $\mathrm{CH}_{2}, \mathrm{C}=\mathrm{O}, \mathrm{Ar}-\mathrm{C}-\mathrm{H}, \mathrm{SO}$, and C-O-C functional groups, respectively. Thus, all the FT-IR spectra characteristics (Supplementary Figure S1) illustrate the successful synthesis of the monofunctionalized phthalocyanine complex. The mass spectrum of the complex also confirmed the structure as $\mathrm{m} / \mathrm{z} 1774$ $[\mathrm{M}+2 \mathrm{H}]+($ Supplementary Figure S2). 
Considering FT-IR spectra of the synthesized ASG20 complex (Supplementary Figure $\mathrm{S} 1$ ), the peaks observed at $2928 \mathrm{~cm}^{-1}, 1712 \mathrm{~cm}^{-1}, 1462 \mathrm{~cm}^{-1}, 1290 \mathrm{~cm}^{-1}, 1140 \mathrm{~cm}^{-1}$, and $660 \mathrm{~cm}^{-}$ ${ }^{1}$ represent aliphatic $\mathrm{CH}_{2}, \mathrm{C}=\mathrm{O}$, Ar-C-H, SO, C-O-C, and S-S (specific to the dimeric PS) functional groups, respectively. Thus, all the FT-IR spectra characteristics (Supplementary Figure S1) illustrate the successful synthesis of the ASG20 complex. The mass spectrum of the complex also confirmed the structure as m/z $3661[\mathrm{M}+]+$ (Supplementary Figure S2). When $1 \mathrm{H}$ NMR and 13C-NMR spectra were examined, it was observed that symmetrical phthalocyanines were intertwined, causing the spectra to not be seen clearly.

In our study, examination of all variables could be achieved by synthesizing reference molecules in addition to the disulfide-linked dimer (ASG20 complex) that became active with GSH in order to produce a meaningful outcome. One of the reference substances synthesized was the analog dimer (REF1), which carries $-\mathrm{C}=\mathrm{C}$ - instead of disulfide and does not interact with GSH. The other analog reference was an "AB3 type" monomer (REF2) that forms by the cleavage of the disulfide bridge of the ASG20 complex (Figure 1).

Considering FT-IR spectra of the synthesized reference dimer complex (REF1) (Supplementary Figure S1), the peaks observed at $2927 \mathrm{~cm}^{-1}, 1624 \mathrm{~cm}^{-1}, 1569 \mathrm{~cm}^{-1}, 1309 \mathrm{~cm}^{-}$ 1, and $1242 \mathrm{~cm}^{-1}$ represent aliphatic $\mathrm{CH} 2, \mathrm{C}=\mathrm{C}$ (specific to this dimeric structure), aliphatic $\mathrm{CH} 3, \mathrm{SO}, \mathrm{C}-\mathrm{O}-\mathrm{C}$ functional groups, respectively. Thus, all the FT-IR spectra characteristics (Supplementary Figure S1) illustrate the successful synthesis of the REF1 complex. The mass spectrum of the complex also confirmed the structure as m/z TRANS $3661[\mathrm{M}+\mathrm{K}]+$ (Supplementary Figure S2). When 1H NMR and 13C-NMR spectra were examined, it was observed that symmetrical phthalocyanines were intertwined, causing the spectra to not be seen clearly.

Considering FT-IR spectra of the synthesized reference monomer complex (REF2) (Supplementary Figure S1), the peaks observed at $2927 \mathrm{~cm}^{-1}, 1570 \mathrm{~cm}^{-1}$, and $1309 \mathrm{~cm}^{-1}$ represent aliphatic $\mathrm{CH}_{2}$, Ar-C-H, and $\mathrm{SO}$ functional groups, respectively. Thus, all the characteristics of the FT-IR spectra (Supplementary Figure S1) illustrate the successful synthesis of the REF2 complex. The complex's mass spectrum also confirmed the structure as m/z $1841[\mathrm{M}+\mathrm{K}]+$ (Supplementary Figure S2). When 1H NMR and 13C-NMR spectra were examined, it was observed that symmetrical phthalocyanines were intertwined, causing the spectra to not be seen clearly.

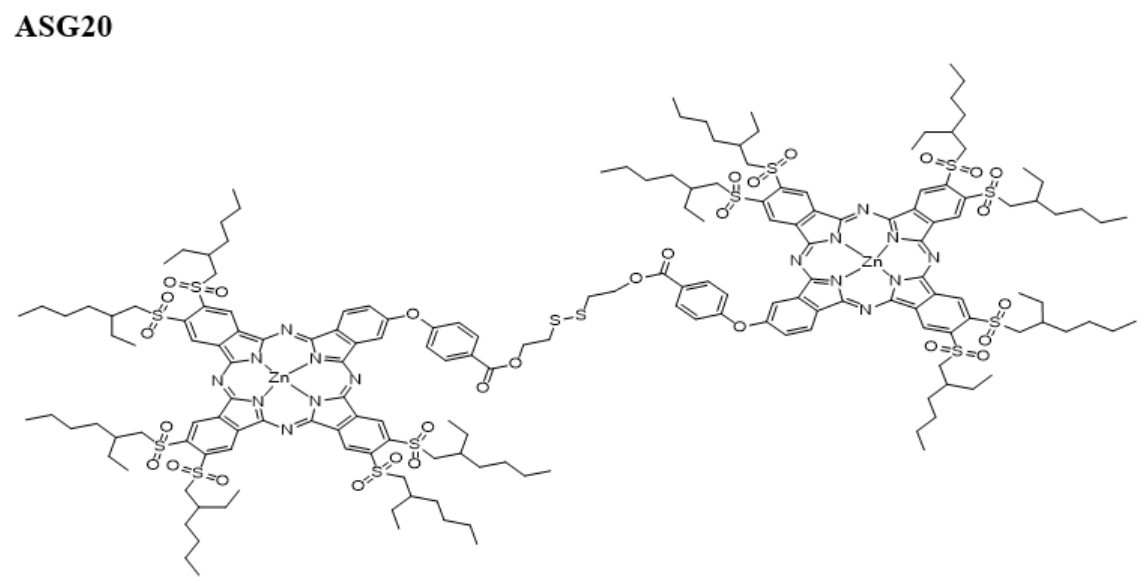




\section{REF1}

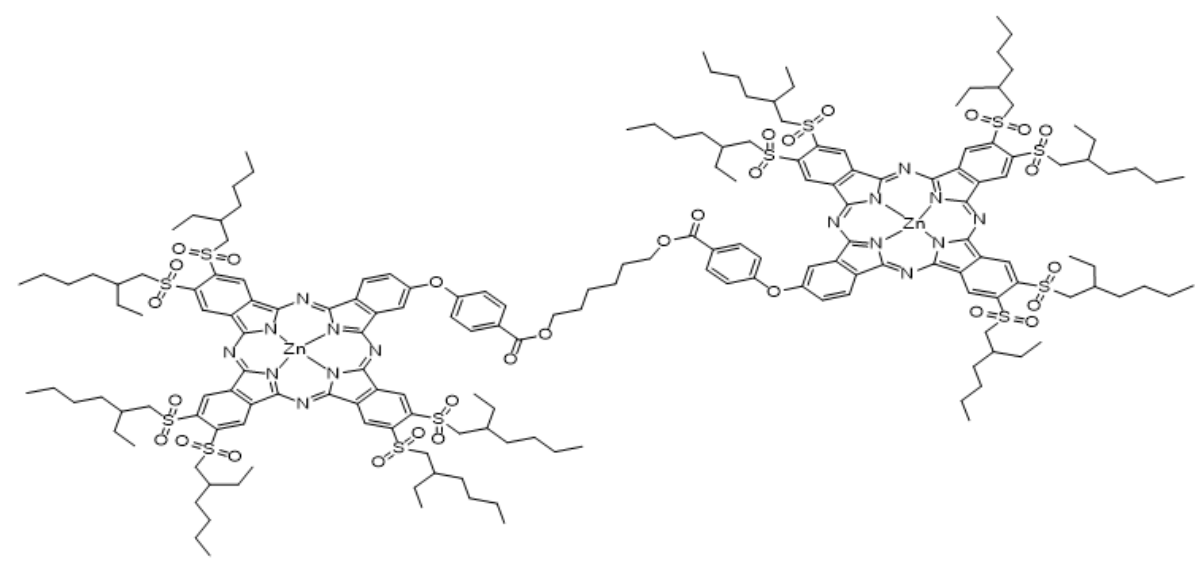

REF2

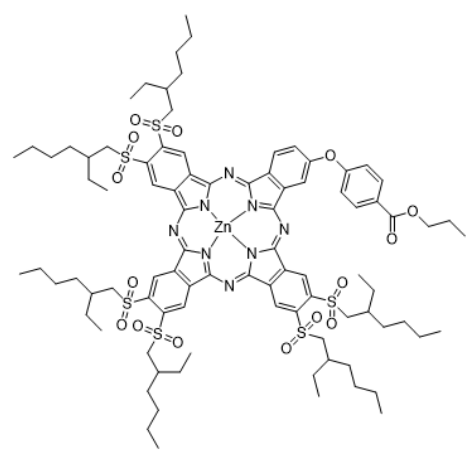

Figure 1. Molecular structures of the synthesized reference monomer analog (REF2), reference dimer analog (REF1), and dimeric phthalocyanine complex (ASG20).
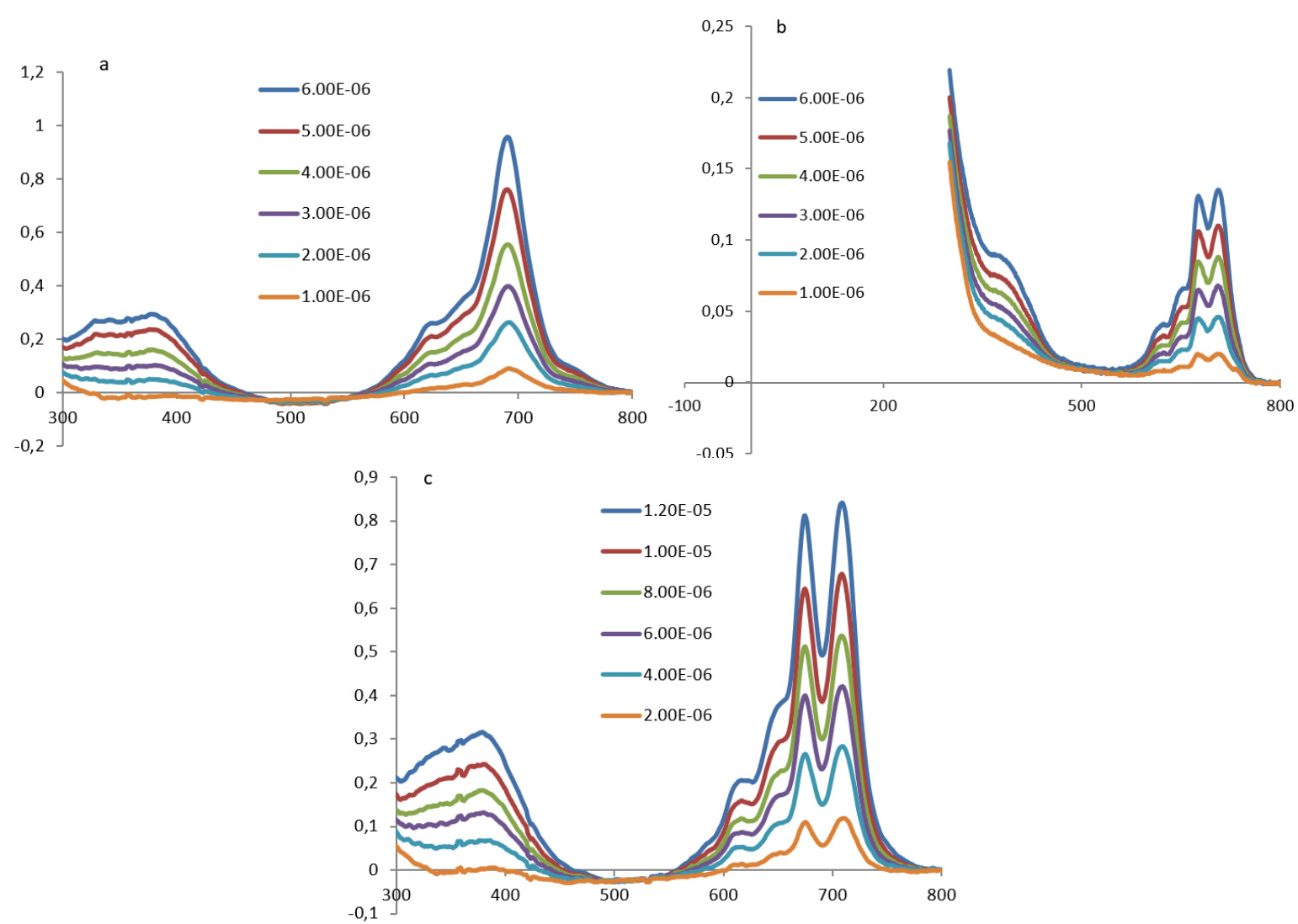

Figure 2. UV-visible spectra of the samples prepared from the $10^{-6} \mathrm{M}$ solution of ASG20 (a), REF1 (b) and REF2 (c) dissolved in DMSO. 
The UV-visible spectrum of the samples prepared from the concentrated solution of ASG20, REF1, and REF2 dissolved in DMSO showed that the intensity of absorption raised in direct proportion to the increase in concentration (Figure 2). The UV-visible spectra of the synthesized ASG20 complex illustrate that the complex with a wavelength absorbance value of $685 \mathrm{~nm}$ is an ideal molecule for PDT since between 650 and $800 \mathrm{~nm}$ is a therapeutic window for clinical PDT treatment, in which light can deeply penetrate the skin $[17,18]$.

\subsection{Characterization of synthesized liposomes containing phthalocyanines.}

In aqueous medium, hydrophobic PSs, including metal phthalocyanines (e.g., zinc(II) phthalocyanines in the current study) are photochemically inactive due to aggregation; hence, to overcome this limitation and minimize the problems under physiological conditions, they need to be encapsulated [2, 12, 28-31, 37]. In this context, due to their highly advantageous features (such as enabling passive and active targeting, lowering the cytotoxicity of the agents to normal tissues, carrying neutral, hydrophilic, and hydrophobic molecules, increasing the solubility of hydrophobic molecules, and enabling a prolonged and controlled release of agents) $[29,33]$, the dimeric form of the synthesized zinc(II) phthalocyanine molecules have been encapsulated in liposome nanoparticles.

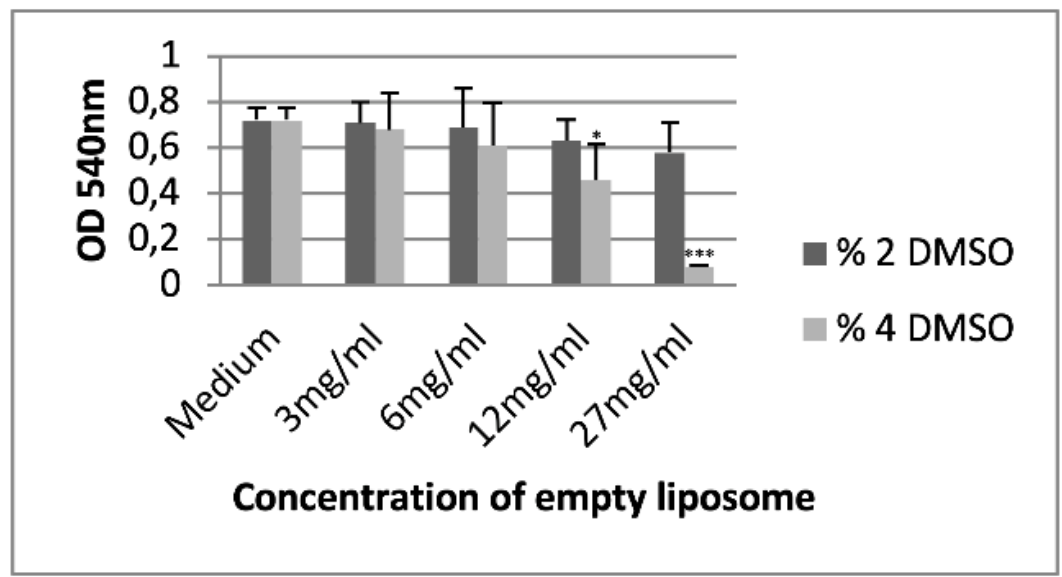

Figure 3. MTT assay of the empty liposome nanoparticles at different concentrations to adjust the optimal liposome dose. Significant difference with respect to medium is denoted as *p-value $<0.05$ and $* * * \mathrm{p}$-value $<$ 0.001 .

For this purpose, initially, the empty liposomes at 3, 6, 12, and $27 \mathrm{mg} / \mathrm{mL}$ concentrations in DMSO (2\% or $4 \%$ ) were analyzed by MTT assay to determine optimal liposome concentration that does not cause a significant effect on the viability of MCF-7 cells (Figure 3). In this context, $6 \mathrm{mg} / \mathrm{mL}$ was determined as the optimal concentration of liposomes to encapsulate the synthesized phthalocyanines (Figure 3).

Dimensions, distribution indexes (PDI), and zeta potentials of PS containing liposomes were characterized by Zetasizer. The nanoparticles' average dimensions were found to be in the range of $167.6 \mathrm{~nm}-226.4 \mathrm{~nm}$ (Figure 4 and Table 1). Through the EPR effect, nanomedicine formulations with sizes typically in the 100-200 $\mathrm{nm}$ range attempt to target sites, but the formulations with sizes up to $400 \mathrm{~nm}$ have demonstrated accumulation in tumors [38]. Therefore, liposome nanoparticles containing disulfide bridged phthalocyanines (ASG20) have favorable sizes for effective therapeutic approaches. The PDI range was between 0.108-0.241, which was less than 0.5, achieving the desired narrow distribution (Table 1). PDI is an indicator of the distribution of size populations within a given sample; PDI value ranges from 0.0 to 1.0 
(0.0 represents a perfectly uniform sample distribution, 1.0 represents highly polydisperse distribution) $[26,39,40]$. Thus, the PDI value that is close to zero illustrate that the liposome nanoparticles have high aqueous stability in the conditions in which they are to be used; and this stability makes the liposome nanoparticles containing disulfide bridged phthalocyanines (ASG20) attractive vehicles for biomedical applications [26, 40-43].

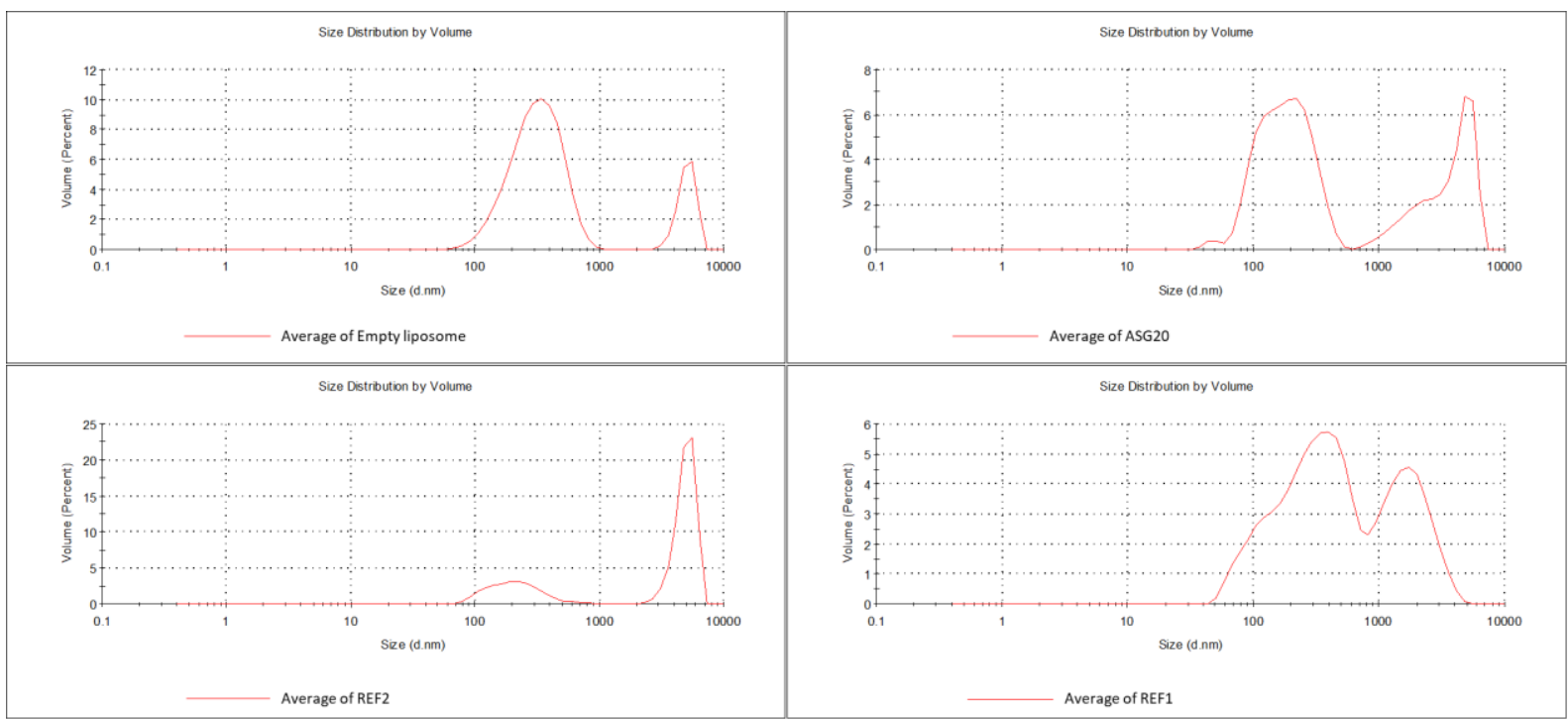

Figure 4. The average sizes of empty liposome nanoparticles, and ASG20, REF1 and REF2 containing liposom nanoparticles recorded by Zetasizer.

Table 1. The average size and PDI values of empty liposome nanoparticles, and ASG20, REF2 and REF1 containing liposom nanoparticles measured by Zetasizer.

$\begin{array}{lcr} & \text { Average Size of Particle } & \text { Polydispersity Index }(\text { P } \\ \text { Empty liposome } & 226.4 \mathrm{~nm} & 0.149 \\ \text { REF0 } & 213.6 \mathrm{~nm} & 0.227 \\ \text { REF1 } & 198.4 \mathrm{~nm} & 0.225 \\ \text { REF2 } & 212.6 \mathrm{~nm} & 0.241 \\ \text { ASG20 } & 167.6 \mathrm{~nm} & 0.108\end{array}$

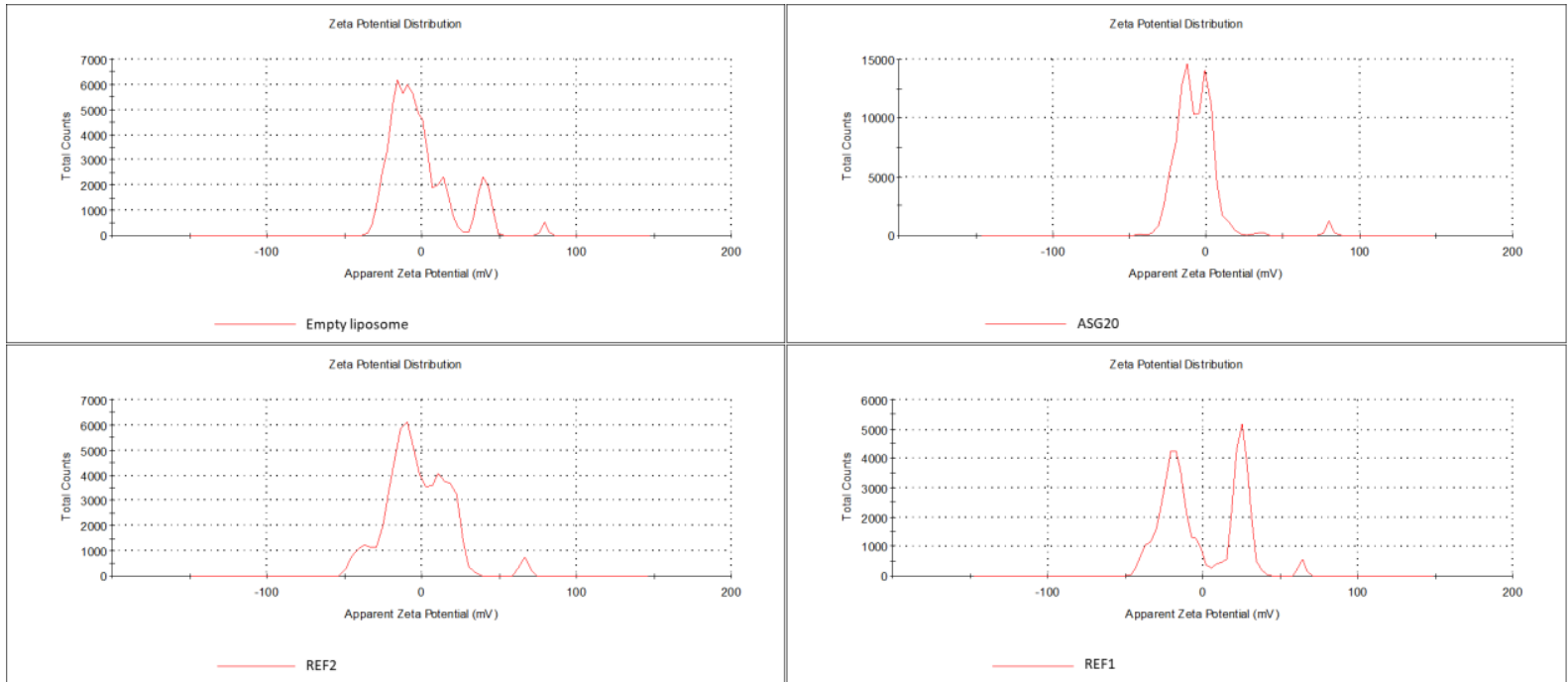

Figure 5. The Zeta potential measurements of empty liposome nanoparticles and ASG20, REF2, and REF1 containing liposome nanoparticles recorded by Zetasizer.

The zeta potential is often considered as the effective charge on the particle, and the zeta potential value of the nanoparticles is sensitive to the ambient $\mathrm{pH}$ value; acidic $\mathrm{pH}$ causes a positive zeta potential value due to the increase in $\mathrm{H}+$ ion concentration, while basic $\mathrm{pH}$ 
causes negative zeta potential value due to the increase in $\mathrm{OH}$ - ion concentration [26, 44-46].

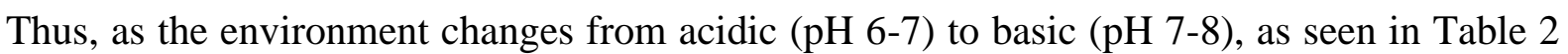
(except for REF2, which may be due to its monomeric nature), the zeta potential is expected to be more negative.

Table 2. The Zeta potential measurements of empty liposome nanoparticles and ASG20, REF2, and REF1 containing liposome nanoparticles recorded by Zetasizer.

$\begin{array}{lcr} & \text { Zeta Potential }(\mathbf{m V})(\mathbf{p H} \text { 6-7) } & \text { Zeta Potential }(\mathbf{m V})(\mathbf{p H} \\ \text { Empty liposome } & -1.15 & -1.62 \\ \text { REF1 } & -1.47 & -3.40 \\ \text { REF2 } & -3.96 & -0.81 \\ \text { ASG20 } & -6.36 & -7.12\end{array}$

\subsection{Cytotoxicity of photosensitizers on MCF-7 Cells.}

Since the gradual increase in cancer in the modern world makes it important to develop an effective treatment strategy, third-generation PSs have been developed to provide selective accumulation in cancer cells [47]. In addition to tumor targeting, tumor-specific activation capability (dual effect) can help to reduce the amount of applied PS, can prevent any damage to the healthy cells in the irradiated region, and may help to distinguish the tumor cell from healthy cells.

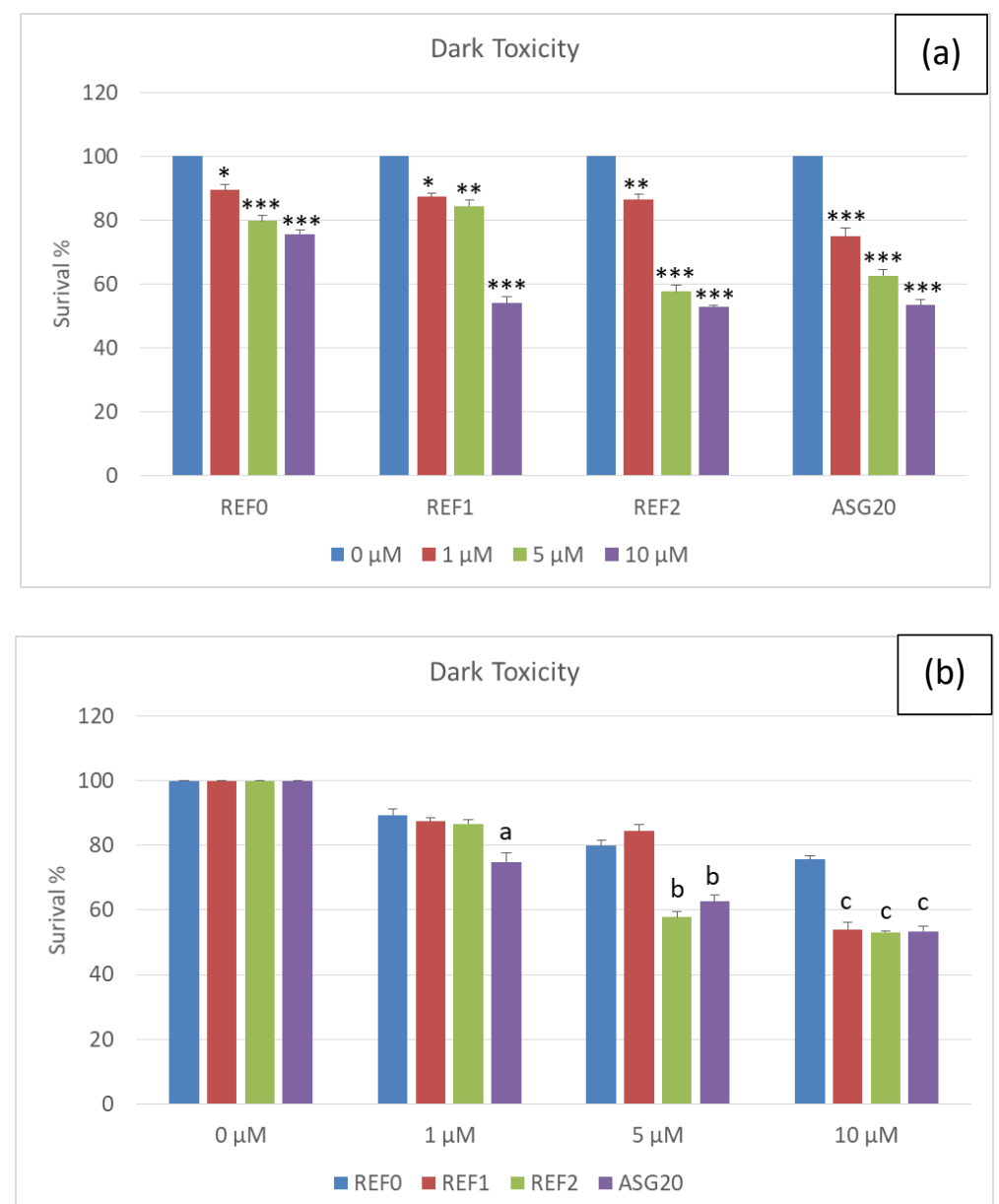

Figure 6. Survival ratios of MCF-7 cancer cells analyzed by dark toxicity assays using different concentrations of liposome nanoparticles containing REF0, REF1, REF2 and ASG20. (a): Effects of different concentrations of each compound on the viability of MCF-7 cancer cells; (b): Effects of different compounds at a specific concentration on the viability of MCF-7 cancer cells. $* \mathrm{P}<0.05$, $* * \mathrm{P}<0.01$ and $* * * \mathrm{P}<0.001$ vs $0 \mu \mathrm{M}$ group. a: $\mathrm{P}<0.001$ vs REF0, REF1 and REF2 groups; $\mathrm{b}$ : $\mathrm{P}<0.001$ vs REF0 and REF1 groups; $\mathrm{c}$ P < 0.001 vs REF0 group. 
Thus, in this study, we developed a disulfide bridged phthalocyanine containing liposomes, which accumulate selectively in cancer cells by EPR effect and especially active in the tumor zone through dividing the disulfide bridges with the antioxidant property of GSH (tumor cells have four times higher GSH concentration than that of normal cells [23, 26]), a tripeptide containing thiol function in tumor cells; the dimeric PSs with the disulfide bridges are in a self-damping (inactive) state for PDT until the disulfide bridges break.

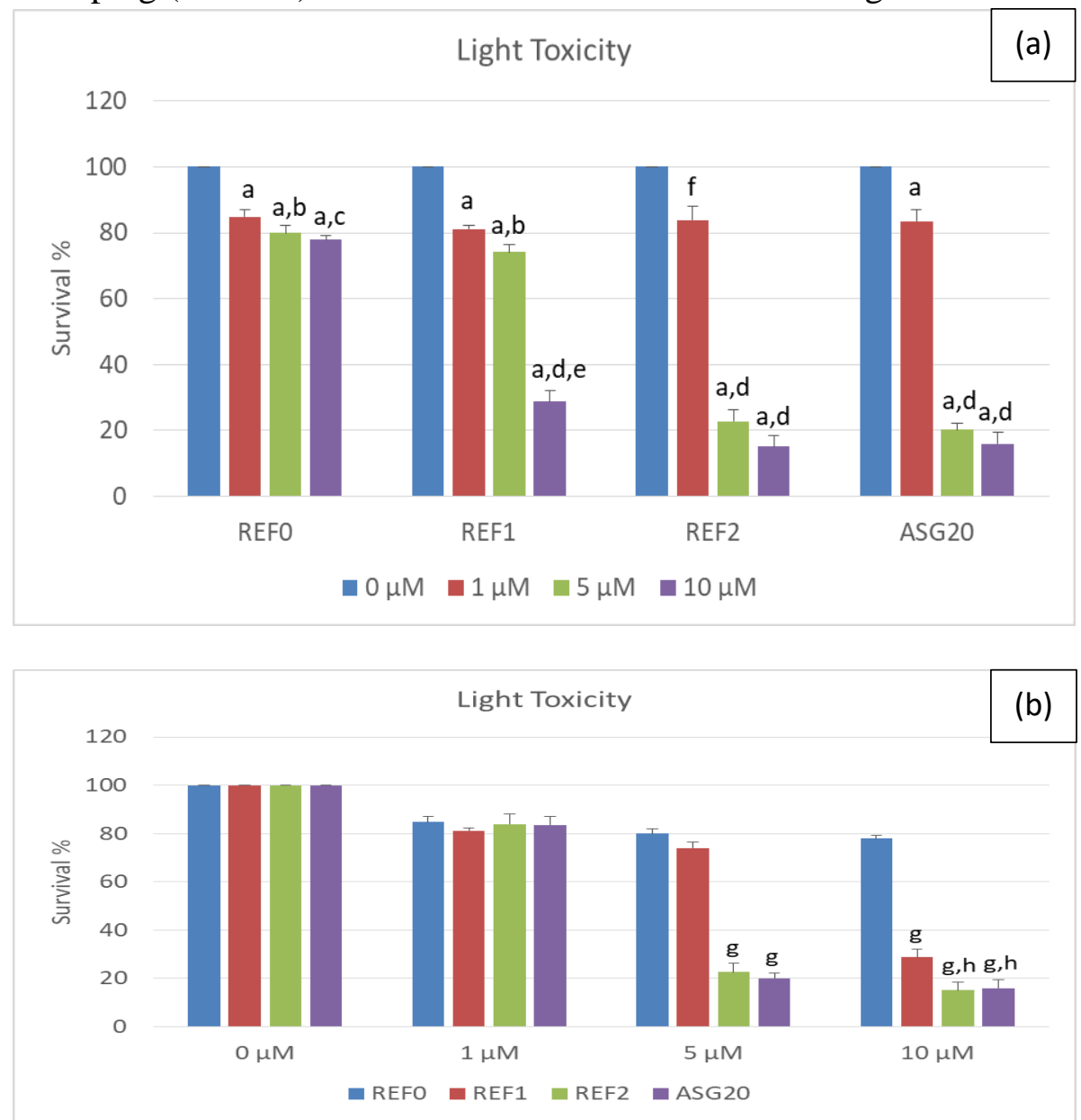

Figure 7. Survival ratios of MCF-7 cancer cells analyzed by phototoxicity assay using different concentrations of liposome nanoparticles containing REF0, REF1, REF2 and ASG20 illuminated by $5 \mathrm{j} / \mathrm{cm} 2$ dose of light. (a):

Effects of different concentrations of each compound on the viability of MCF-7 cancer cells; (b): Effects of different compounds at a specific concentration on the viability of MCF-7 cancer cells. aP $<0.001$, fP $<0.01$ vs $0 \mu \mathrm{M}$ group; $\mathrm{bP}<0.05, \mathrm{cP}<0.01, \mathrm{dP}<0.001$ vs $1 \mu \mathrm{M}$ group; $\mathrm{eP}<0.001$ vs $5 \mu \mathrm{M}$ group; $\mathrm{gP}<0.0001$ vs $\mathrm{REF} 0$ and REF1; hP $<0.01$ vs REF1.

The dark toxicity results illustrated that cells' survival ratios decreased in proportional to the concentration of phthalocyanine-containing liposomes (Figure 6). At a $10 \mu \mathrm{M}$ concentration, the viability decreased more than $40 \%$ in ASG20, REF2, and REF1 groups, while it was more than $20 \%$ in REF0 group ( $p<0.001$ for REF0 vs. ASG20, REF2, and REF1 groups). At $5 \mu \mathrm{M}$ concentration, a reduction of approximately $40 \%$ of viability was observed in ASG20 and REF2 groups, and approximately 20\% in REF0 and REF1 groups ( $p<0.001$ for REF0 and REF1 groups vs. ASG20 and REF2 groups). REF2 was an active monomeric molecule that was synthesized as a reference to prove that the cleavage of disulfide bridges of ASG20 resulted in the activation of ASG20, which is a dimeric PS. If the disulfide bridges in the ASG20 structure had not been broken, it would have had a similar toxic effect as REF1. ASG20 showed similar toxicity to REF2; that is, ASG20 transformed into its active monomer REF2 by cleavage of the disulfide bonds of ASG20 by GSH in cancer cells. On the other hand, 
GSH cannot cleave carbon-carbon bonds in REF1 structures; hence REF1 could not be active in cancer cells. These results illustrate that the synthesized disulfide bridged phthalocyanine (ASG20) is an activatable molecule in MCF-7 cancer cells by the GSH activity.

In the present study, when a certain concentration $(1,5,10 \mu \mathrm{M})$ of PS containing liposomes were applied to MCF-7 cells, and when a light source (EFOS LED array $~ 690 \mathrm{~nm}$, $5 \mathrm{j} / \mathrm{cm} 2$ ) was used for light toxicity assays, it was observed that the viability of cells decreased significantly with the increase in the dose (Figure 7). At $5 \mu \mathrm{M}$ liposome concentration, the viability of cells decreased by about $80 \%$ in the ASG20 and REF2 groups, while it decreased by about $20 \%$ in the REF0 and REF1 groups ( $p<0.0001$ for REF0 and REF1 groups vs. ASG20 and REF2 groups). Thus, light toxicity is suggested to begin at $5 \mu \mathrm{M}$ concentration of PScontaining liposomes.

One of the desirable properties of an ideal PS is to have minimum toxicity in the dark and high toxicity in the light. According to MTT results of the present study, this was achieved at a liposome concentration of $5 \mu \mathrm{M}$. Disulfide bridged phthlocyanine (ASG20) containing liposomes applied at $5 \mu \mathrm{M}$ concentration to MCF-7 cells showed minimal toxicity in the dark, while the application resulted in a survival ratio of approximately $20 \%$ in light, which is approximately one-third of the survival ratio $(\sim 60 \%)$ in the dark (Figure 8$)$. As the desired result, we suggest that the monomer reference (REF2) shows a similar survival rate with ASG20, which is activated specifically in the tumor while the dimer reference (REF1) does not show the same survival rate in comparison with ASG20. The fluorescent images obtained from dark and light toxicity experiments by using a fluorescence microscope also prove this statement (Figure 9). REF1 had no significant effect on the structures of cells and cell clusters in the dark and light environment; however, probably due to the increasing levels of apoptosis or necrosis, REF2 and ASG20 treatment resulted in shrinkage of cells that lost their intercellular connections as well as a disruption in the cell clusters (Figure 9). To clarify these cells' death pathway, we did flow cytometric analysis and presented it in the coming section.

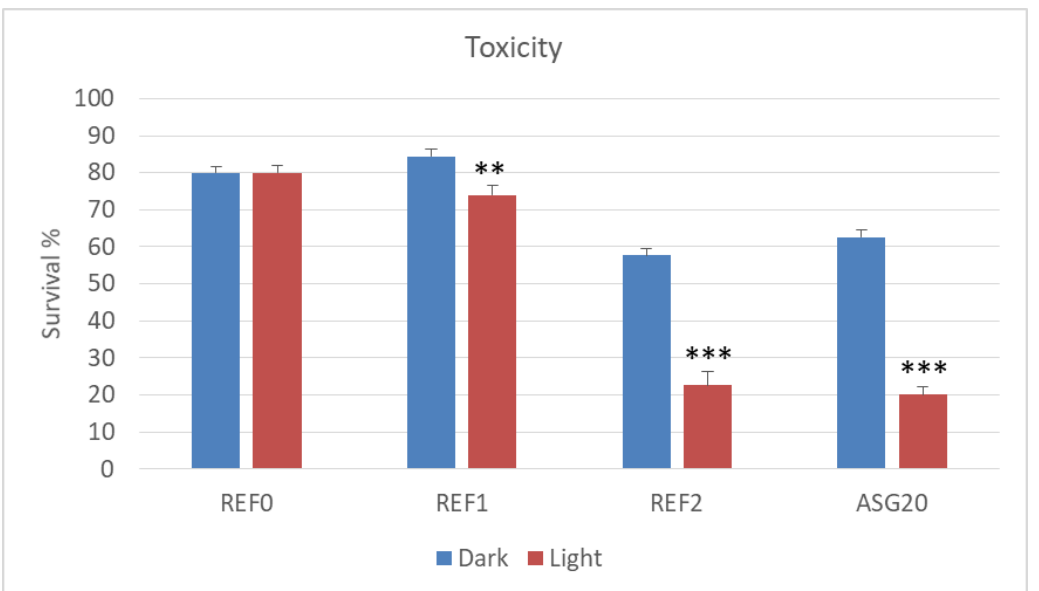

Figure 8. Survival ratios of MCF-7 cancer cells incubated with liposome nanoparticles containing $5 \mu \mathrm{M}$ of REF0, REF1, REF2, and ASG20, analyzed by dark and light toxicity assays. **P < 0.01 , ***P $<0.001$ vs dark groups.

\subsection{Apoptotic and necrotic findings of the flow-cytometric assay.}

In the present study, a flow cytometric assay was performed to investigate the indexes of programmed cell death preferred by cells incubated with liposomes containing $5 \mu \mathrm{M}$ of PS under the light of $5 \mathrm{j} / \mathrm{cm} 2$. Since the percentages of necrotic cells were extremely low 
compared with the apoptotic cells, the induced cell death was mostly driven by apoptosis rather than necrosis. The apoptotic rates of cells in ASG20 group was approximately 60\%, which was significantly $(\mathrm{p}<0.05)$ higher than the rates of cells incubated with empty liposome. REF2 group showed an apoptotic rate of more than $40 \%$, while REF1 group presented a rate between $30-40 \%$ (Figure 10).

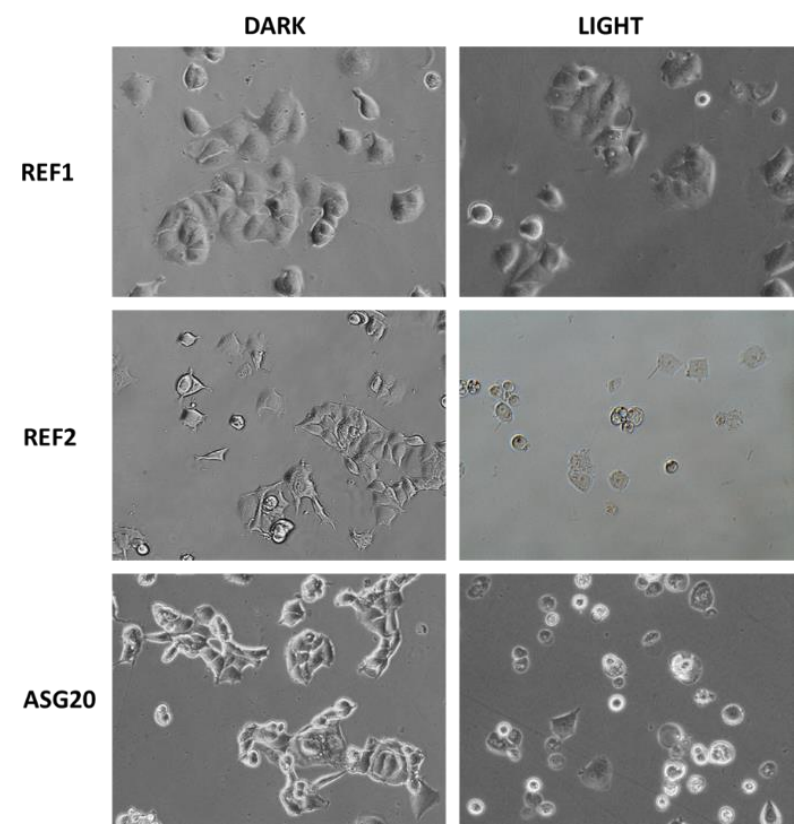

Figure 9. Fluorescent microscopic images of liposomes with photosensitizers representing dark-light toxicity (Magnification: 20X, concentration of photosensitizers: $5 \mu \mathrm{M}$ ).

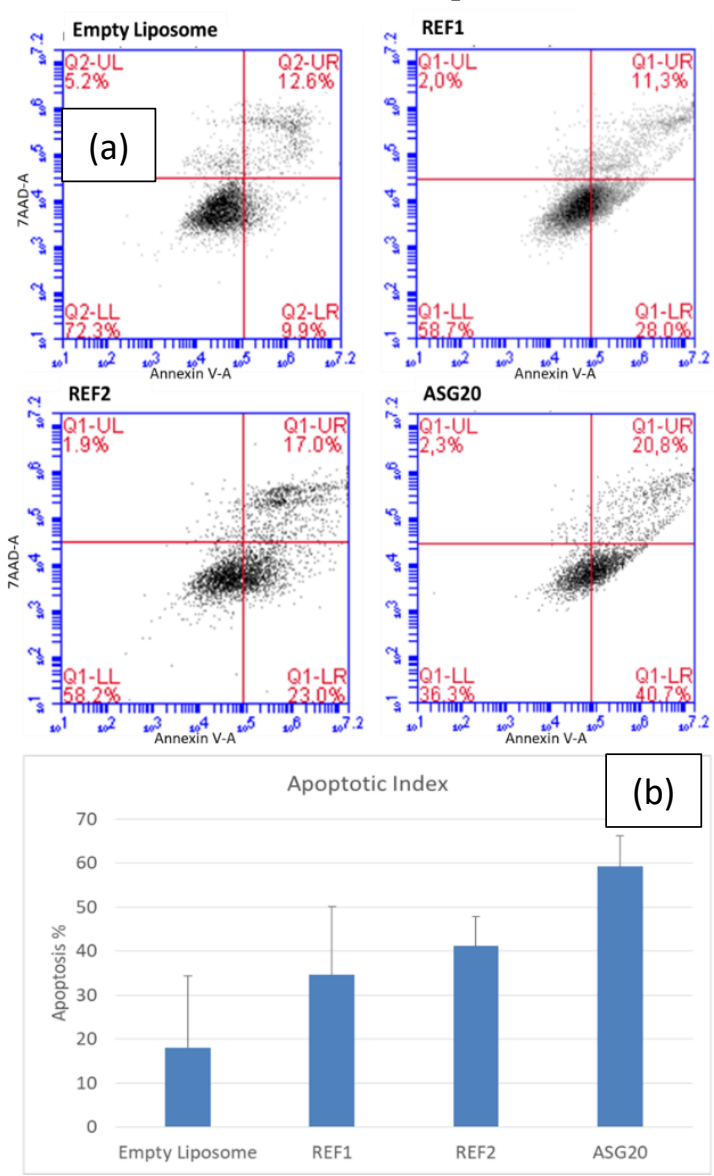

Figure 10. Flow cytometric graphs (a) and apoptotic indexes (b) of MCF-7 cells incubated with empty liposomes and with liposomes containing $5 \mu \mathrm{M}$ of REF0, REF1, REF2, and ASG20. *P $<0.05$ vs empty liposome group. 
In the very first place, hematoporphyrin was used as a first-generation PS for PDT of cancers [48]. Albeit having a high singlet oxygen yield, this molecule has disadvantages of not being absorption effective at low wavelengths and low selectivity in healthy cells. As a secondgeneration PS, tetrapyrrole derivatives have been used, which are considered well-defined uniform drugs in PDT [49]. Nowadays, the effectiveness of third-generation PSs has been developed either by combining the effect of PS unit with its imaging feature or by increasing the distribution of activation of PSs in tumors. Recent works have focused on the accumulation of PSs together with their effectiveness at the tumor site [50]. Hence, the amount of the curing PS can be reduced, and the radiation may be less damaging to healthy cells. As one of the main issues of PDT, the patient becomes sensitive to the light as a result of penetration of the medication to the healthy cells; hence the patient has to avoid sunlight for up to 6 weeks to be cured [51]. Thus, with further verification studies, the synthesized disulfide-bridged dimeric phthalocyanine (ASG20) containing liposomes have a great potential for modern PDT.

\section{Conclusions}

In conclusion, the results revealed by the current study illustrated that: I- The synthesized disulfide bridged phthalocyanine (ASG20) has therapeutically active wavelength absorbance value $(685 \mathrm{~nm})$; II- In terms of physicochemical characteristics such as hydrodynamic size, zeta potential, and PDI values, the ASG20 containing liposome nanoparticles are attractive vehicles for biomedical applications; III- In addition to the attractive physicochemical properties, the ASG20 containing liposome nanoparticles have the ability to be selectively activated in cancer cells depending on the high concentration of GSH in cancer cells; IV- Moreover, the ASG20 containing liposome nanoparticles have low dark toxicity, and significant light toxicity $(\mathrm{P}<0.001$ vs. dark toxicity) characterized with significant apoptosis ( $\mathrm{p}<0.05 \mathrm{vs}$. control group).

As a future consideration of the present study, in vitro studies with non-tumoral cells, including ROS production measurements or even $3 \mathrm{D}$ cultures, would be interesting with the appropriate controls. In fact, the ultimate approach may be determining the efficiency and safety of the PDT comparing with or combining with other chemotherapies by performing in vivo experiments in the future. Further investigations on these research topics are ongoing in our laboratory.

\section{Funding}

This research was funded by the Marmara University Scientific Research Projects Unit, grant number SAG-C-DRP-090217-0043.

\section{Acknowledgments}

The authors declare no conflict of interest. The funders had no role in the design of the study, in the collection, analyses, or interpretation of data, in the writing of the manuscript, or in the decision to publish the results.

\section{Conflicts of Interest}

The authors declare no conflict of interest. 


\section{References}

1. Bray, F.; Ferlay, J.; Soerjomataram, I.; Siegel, R.L.; Torre, L.A.; Jemal, A. Global cancer statistics 2018: GLOBOCAN estimates of incidence and mortality worldwide for 36 cancers in 185 countries. CA Cancer J. Clin 2018, 68, 394-424, https://doi.org/10.3322/caac.21492.

2. Chen, J.; Fan, T.; Xie, Z.; Zeng, Q.; Xue, P.; Zheng, T.; Chen, Y.; Luo, X.; Zhang, H. Advances in nanomaterials for photodynamic therapy applications: Status and challenges. Biomaterials 2020, 237, 119827, https://doi.org/10.1016/j.biomaterials.2020.119827.

3. Gokduman, K. In vitro investigation of anti-cancer activity of propolis on hepatocellular carcinoma cells. Med-Science 2019, 8, 557-562, https://doi.org/10.5455/medscience.2019.08.9013.

4. Hou, X.; Tao, Y.; Pang, Y.; Li, X.; Jiang, G.; Liu, Y. Nanoparticle-based photothermal and photodynamic immunotherapy for tumor treatment. Int. J. Cancer 2018, 143, 3050-3060, https://doi.org/10.1002/ijc.31717.

5. Diaz, E.M.J.; Sturgis, E.M.; Laramore, G.E.; Sabichi, A.L.; Lippman, S.M.; Clayman, G. Neoplasms of the Head and Neck. In: Holland-Frei Cancer Medicine. 6th ed.; Editors: Kufe, D.W.; Pollock, R.E.; Weichselbaum, R.R.; Bast, R.C.; Gansler, T.S.; Holland, J.F.; Frei, E.; BC Decker Inc.: Hamilton (ON), USA, 2003.

6. De Angelis, C. Side effects related to systemic cancer treatment: are we changing the Promethean experience with molecularly targeted therapies? Curr. Oncol 2008, 15, 198-199, https://doi.org/10.3747/co.v15i4.362.

7. Kaufman, H.L.; Russell, J.; Hamid, O.; Bhatia, S.; Terheyden, P.; D'Angelo, S.P.; Shih, K.C.; Lebbé, C.; Linette, G.P.; Milella, M.; Brownell, I.; Lewis, K.D.; Lorch, J.H.; Chin, K.; Mahnke, L.; von Heydebreck, A.; Cuillerot, J.M.; Nghiem, P. Avelumab in patients with chemotherapy-refractory metastatic Merkel cell carcinoma: a multicentre, single-group, open-label, phase 2 trial. Lancet Oncol 2016, 17, 1374-1385, https://doi.org/10.1016/S1470-2045(16)30364-3.

8. Lamberti, M.J.; Vittar, N.B.; Rivarola, V.A. Breast cancer as photodynamic therapy target: Enhanced therapeutic efficiency by overview of tumor complexity. World J. Clin. Oncol 2014, 5, 901-907, https://doi.org/10.5306/wjco.v5.i5.901.

9. Chizenga, E.P.; Abrahamse, H. Nanotechnology in modern photodynamic therapy of cancer: A review of cellular resistance patterns affecting the therapeutic response. Pharmaceutics 2020, 12, https://doi.org/10.3390/pharmaceutics12070632.

10. Cho, Y.; Choi, Y. Graphene oxide-photosensitizer conjugate as a redox-responsive theranostic agent. Chem. Commun. (Camb) 2012, 48, 9912-9914, https://doi.org/10.1039/c2cc35197h.

11. Kiew, L.V.; Cheah, H.Y.; Voon, S.H.; Gallon, E.; Movellan, J.; Ng, K.H.; Alpugan, S.; Lee, H.B.; Dumoulin, F.; Vicent, M.J.; Chung, L.Y. Near-infrared activatable phthalocyanine-poly-L-glutamic acid conjugate: increased cellular uptake and light-dark toxicity ratio toward an effective photodynamic cancer therapy. Nanomedicine 2017, 13, 1447-1458, https://doi.org/10.1016/j.nano.2017.02.002.

12. Zhang, Y.; Wang, B.; Zhao, R.; Zhang, Q.; Kong, X. Multifunctional nanoparticles as photosensitizer delivery carriers for enhanced photodynamic cancer therapy. Mater. Sci. Eng. C Mater. Biol. Appl 2020, 115, https://doi.org/10.1016/j.msec.2020.111099.

13. van Straten, D.; Mashayekhi, V.; de Bruijn, H.S.; Oliveira, S.; Robinson, D.J. Oncologic photodynamic therapy: Basic principles, current clinical status and future directions. Cancers (Basel) 2017, 9, https://doi.org/10.3390/cancers9020019.

14. Castano, A.P.; Demidova, T.N.; Hamblin, M.R. Mechanisms in photodynamic therapy: Part threePhotosensitizer pharmacokinetics, biodistribution, tumor localization and modes of tumor destruction. Photodiagnosis Photodyn. Ther 2005, 2, 91-106, https://doi.org/10.1016/S1572-1000(05)00060-8.

15. Xiao, Q.; Wu, J.; Pang, X.; Jiang, Y.; Wang, P.; Leung, A.W.; Gao, L.; Jiang, S.; Xu, C. Discovery and development of natural products and their derivatives as photosensitizers for photodynamic therapy. Curr. Med. Chem 2018, 25, 839-860, https://doi.org/10.2174/0929867324666170823143137.

16. Zhao, B.; He, Y.Y. Recent advances in the prevention and treatment of skin cancer using photodynamic therapy. Expert Rev. Anticancer Ther 2010, 10, 1797-809, https://doi.org/10.1586/era.10.154.

17. Abrahamse, H.; Hamblin, M.R. New photosensitizers for photodynamic therapy. Biochem. J 2016, 473, 347364, https://doi.org/10.1042/BJ20150942.

18. Martinez De Pinillos Bayona, A.; Mroz, P.; Thunshelle, C.; Hamblin, M.R. Design features for optimization of tetrapyrrole macrocycles as antimicrobial and anti-cancer photosensitizers. Chem. Biol. Drug Des 2017, 89, 192-206, https://doi.org/10.1111/cbdd.12792.

19. Li, X.; Zheng, B.; Peng, X.; Li, S.; Ying, J.; Zhao, Y.; Huang, J.; Yoon, J. Phthalocyanines as medicinal photosensitizers: Developments in the last five years. Coord. Chem. Rev 2019, 379, 147-160, https://doi.org/10.1016/j.ccr.2017.08.003.

20. Roguin, L.P.; Chiarante, N.; García Vior, M.C.; Marino, J. Zinc(II) phthalocyanines as photosensitizers for antitumor photodynamic therapy. Int. J. Biochem. Cell Biol 2019, 114, https://doi.org/10.1016/j.biocel.2019.105575.

21. Allegra, A.; Pioggia, G.; Tonacci, A.; Musolino, C.; Gangemi, S. Oxidative stress and photodynamic therapy of skin cancers: Mechanisms, challenges and promising developments. Antioxidants (Basel) 2020, 9, https://doi.org/10.3390/antiox9050448. 
22. Bilgicli, A.T.; Bilgicli, H.G.; Gunsel, A.; Piskin, H.; Tuzun, B.; Yarasir, M.N.; Zengin, M. The new balltype zinc phthalocyanine with SS bridge; Synthesis, computational and photophysicochemical properties. $J$. Photochem. Photobiol. A 2020,389, https://doi.org/10.1016/j.jphotochem.2019.112287.

23. Bej, R.; Dey, P.; Ghosh, S. Disulfide chemistry in responsive aggregation of amphiphilic systems. Soft Matter 2020, 16, 11-26, https://doi.org/10.1039/c9sm01960j.

24. Chow, S.Y.S.; Zhao, S.; Lo, P.C.; Ng, D.K.P. A cell-selective glutathione-responsive tris(phthalocyanine) as a smart photosensitiser for targeted photodynamic therapy. Dalton Trans 2017, 46, 11223-11229, https://doi.org/10.1039/c7dt02086d.

25. Wong, R.C.H.; Lo, P.; Ng, D.K.P. Stimuli responsive phthalocyanine-based fluorescent probes and photosensitizers. Coord. Chem. Rev 2019, 379, 30-46, https://doi.org/10.1016/j.ccr.2017.10.006.

26. Gokduman, K. Sensitization of cisplatin-resistant ovarian cancer cells by magnetite iron oxide nanoparticles: an in vitro study. Nanomedicine (Lond) 2019, 14, 3177-3191, https://doi.org/10.2217/nnm-2019-0126.

27. Kim, J.; Won, Y.; Goh, S.H.; Choi, Y. A redox-responsive theranostic agent for target-specific fluorescence imaging and photodynamic therapy of EGFR-overexpressing triple-negative breast cancers. J. Mater. Chem. B 2016, 4, 6787-6790, https://doi.org/10.1039/c6tb01519k.

28. Gokduman, K. Strategies targeting DNA Topoisomerase I in cancer chemotherapy: Camptothecins, nanocarriers for camptothecins, organic non-camptothecin compounds and metal complexes. Curr. Drug Targets 2016, 17, 1928-1939, https://doi.org/10.2174/1389450117666160502151707.

29. Montaseri, H.; Kruger, C.A.; Abrahamse, H. Review: Organic nanoparticle based active targeting for photodynamic therapy treatment of breast cancer cells. Oncotarget 2020, 11, 2120-2136, https://doi.org/10.18632/oncotarget.27596.

30. Patra, J.K.; Das, G.; Fraceto, L.F.; Campos, E.V.R.; Rodriguez-Torres, M.D.P.; Acosta-Torres, L.S.; DiazTorres, L.A.; Grillo, R.; Swamy, M.K.; Sharma, S.; Habtemariam, S.; Shin, H.S. Nano based drug delivery systems: recent developments and future prospects. J. Nanobiotechnology 2018, 16, https://doi.org/10.1186/s12951-018-0392-8.

31. Khan, A.U.; Khan, M.; Cho, M.H.; Khan, M.M. Selected nanotechnologies and nanostructures for drug delivery, nanomedicine and cure. Bioprocess Biosyst. Eng 2020, 43, 1339-1357, https://doi.org/10.1007/s00449-020-02330-8.

32. Rios, A.; Batain, F.; Barros, C.; de Paula, D.; Martins, M.; Chaud, M.; Alves, T. Development and validation of a fast and selective HPLC method for the determination of amphotericin B in nose-to-brain nanoliposome. Lett. Appl. NanoBioScience 2021, 10, 2309-2319.

33. Yingchoncharoen, P.; Kalinowski, D.S.; Richardson, D.R. Lipid-based drug delivery systems in cancer therapy: What is available and what is yet to come. Pharmacol. Rev 2016, 68, 701-787, https://doi.org/10.1124/pr.115.012070.

34. Kwiatkowski, S.; Knap, B.; Przystupski, D.; Saczko, J.; Kędzierska, E.; Knap-Czop, K.; Kotlińska, J.; Michel, O.; Kotowski, K.; Kulbacka, J. Photodynamic therapy - mechanisms, photosensitizers and combinations. Biomed. Pharmacother 2018, 106, 1098-1107, https://doi.org/10.1016/j.biopha.2018.07.049.

35. Decreau, R.; Richard, M.J.; Verrando, P.; Chanon, M.; Julliard, M. Photodynamic activities of silicon phthalocyanines against achromic M6 melanoma cells and healthy human melanocytes and keratinocytes. $J$. Photochem. Photobiol. B 1999, 48, 48-56, https://doi.org/10.1016/S1011-1344(99)00008-1.

36. Nombona, N.; Maduray, K.; Antunes, E.; Karsten, A.; Nyokong, T. Synthesis of phthalocyanine conjugates with gold nanoparticles and liposomes for photodynamic therapy. J. Photochem. Photobiol. B 2012, 107, 35-44, https://doi.org/10.1016/j.jphotobiol.2011.11.007.

37. Bolfarini, G.C.; Siqueira-Moura, M.P.; Demets, G.J.F.; Tedesco, A.C. Preparation, characterization, and in vitro phototoxic effect of zinc phthalocyanine cucurbit[7]uril complex encapsulated into liposomes. Dyes Pigm 2014, 100, 162-167, https://doi.org/10.1016/j.dyepig.2013.08.018.

38. Bozzuto, G.; Molinari, A. Liposomes as nanomedical devices. Int. J. Nanomedicine 2015, 10, 975-99, https://doi.org/10.2147/IJN.S68861.

39. Danaei, M.; Dehghankhold, M.; Ataei, S.; Hasanzadeh Davarani, F.; Javanmard, R.; Dokhani, A.; Khorasani, S.; Mozafari, M.R. Impact of particle size and polydispersity index on the clinical applications of lipidic nanocarrier systems. Pharmaceutics 2018, 10, https://doi.org/10.3390/pharmaceutics10020057.

40. Gokduman, K. Comparison of the effect of magnetite (Fe3O4) iron oxide nanoparticles on melanoma cells and healthy cells: an in vitro study. Lett. Appl. NanoBioScience 2020, 9, 1049-1057, https://doi.org/10.33263/LIANBS92.10491057.

41. Paik, S.Y.; Kim, J.S.; Shin, S.J.; Ko, S. Characterization, quantification, and determination of the toxicity of iron oxide nanoparticles to the bone marrow cells. Int. J. Mol. Sci 2015, 16, 22243-22257, https://doi.org/10.3390/ijms160922243.

42. Goncalves, L.C.; Seabra, A.B.; Pelegrino, M.T.; de Araujo, D.R.; Bernardesc, J.S.; Haddad, P.S. Superparamagnetic iron oxide nanoparticles dispersed in Pluronic F127 hydrogel: Potential uses in topical applications. RSC Advances 2017, 7, 14496-14503, https://doi.org/10.1039/C6RA28633J.

43. Gokduman, K.; Gok, A. In vitro investigation of therapeutic potential of bare magnetite $\left(\mathrm{Fe}_{3} \mathrm{O}_{4}\right)$ nanoparticles $(\leq 100 \mathrm{ppm})$ on hepatocellular carcinoma cells. J. Nanosci. Nanotechnol 2020, 20, 1391-1400, https://doi.org/10.1166/jnn.2020.17152. 
44. Patil, S.; Sandberg, A.; Heckert, E.; Self, W.; Seal, S. Protein adsorption and cellular uptake of cerium oxide nanoparticles as a function of zeta potential. Biomaterials 2007, 28, 4600-4607, https://doi.org/10.1016/j.biomaterials.2007.07.029.

45. Pate, K.; Safier, P. Chemical metrology methods for CMP quality. In: Advances in Chemical Mechanical Planarization (CMP). Editors: Babu, S. Woodhead Publishing: 2016; pp. 299-325, https://doi.org/10.1016/C2014-0-01445-1.

46. Illés, E.; Szekeres, M.; Tóth, I.Y.; Farkas, K.; Földesi, I.; Szabó, Á.; Iván, B.; Tombácz, E. PEGylation of superparamagnetic iron oxide nanoparticles with self-organizing polyacrylate-PEG brushes for contrast enhancement in MRI diagnosis. Nanomaterials (Basel). 2018, 8, https://doi.org/10.3390/nano8100776.

47. Kataoka, H.; Nishie, H.; Hayashi, N.; Tanaka, M.; Nomoto, A.; Yano, S.; Joh, T. New photodynamic therapy with next-generation photosensitizers. Ann. Transl. Med 2017, 5, https://doi.org/10.21037/atm.2017.03.59.

48. Ferrand, Y.; Bourré, L.; Simonneaux, G.; Thibaut, S.; Odobel, F.; Lajat, Y.; Patrice, T. Hydroporphyrins as tumour photosensitizers: synthesis and photophysical studies of 2,3-dihydro-5,15-di(3,5-dihydroxyphenyl) porphyrin. Bioorg. Med. Chem. Lett 2003, 13, 833-835, https://doi.org/10.1016/s0960-894x(03)00002-7.

49. Byrne, A.T.; O'Connor, A.E.; Hall, M.; Murtagh, J.; O'Neill, K.; Curran, K.M.; Mongrain, K.; Rousseau, J.A.; Lecomte, R.; McGee, S.; Callanan, J.J.; O'Shea, D.F.; Gallagher, W.M. Vascular-targeted photodynamic therapy with BF2-chelated Tetraaryl-Azadipyrromethene agents: a multi-modality molecular imaging approach to therapeutic assessment. Br. J. Cancer 2009, 101, 1565-1573, https://doi.org/10.1038/sj.bjc.6605247.

50. Naidoo, C.; Kruger, C.A.; Abrahamse, H. Targeted photodynamic therapy treatment of in vitro A375 metastatic melanoma cells. Oncotarget 2019, 10, 6079-6095, https://doi.org/10.18632/oncotarget.27221.

51. Piccolo, D.; Kostaki, D. Photodynamic therapy activated by intense pulsed light in the treatment of nonmelanoma skin cancer. Biomedicines 2018, 6, https://doi.org/10.3390/biomedicines6010018. 


\section{Supplementary materials}

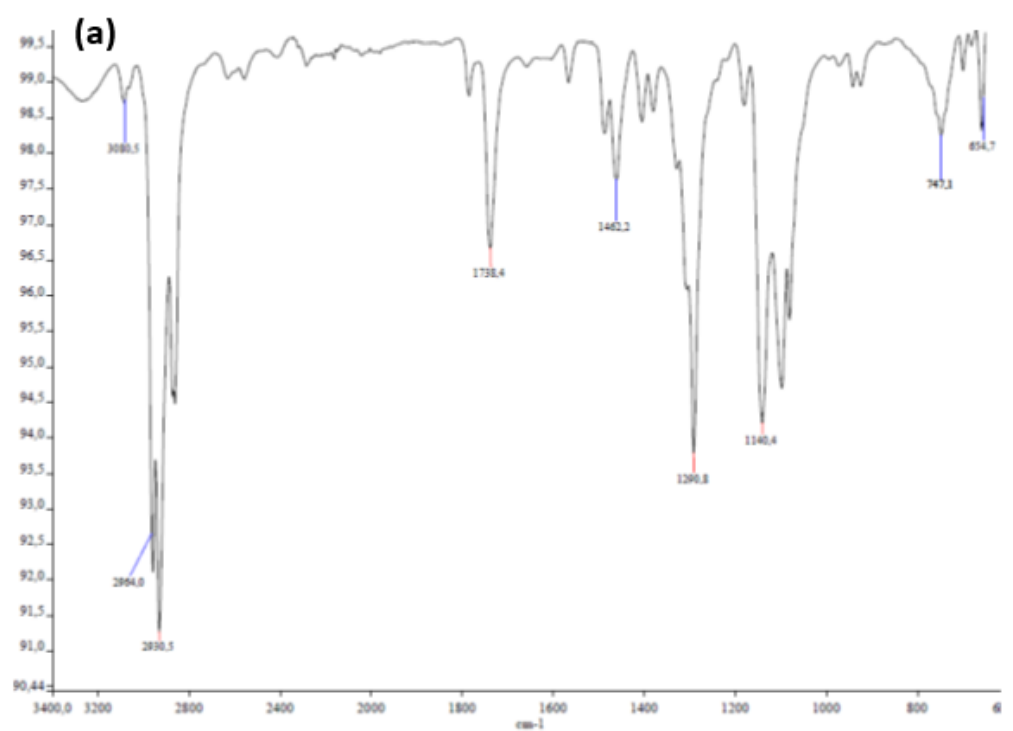

(b)
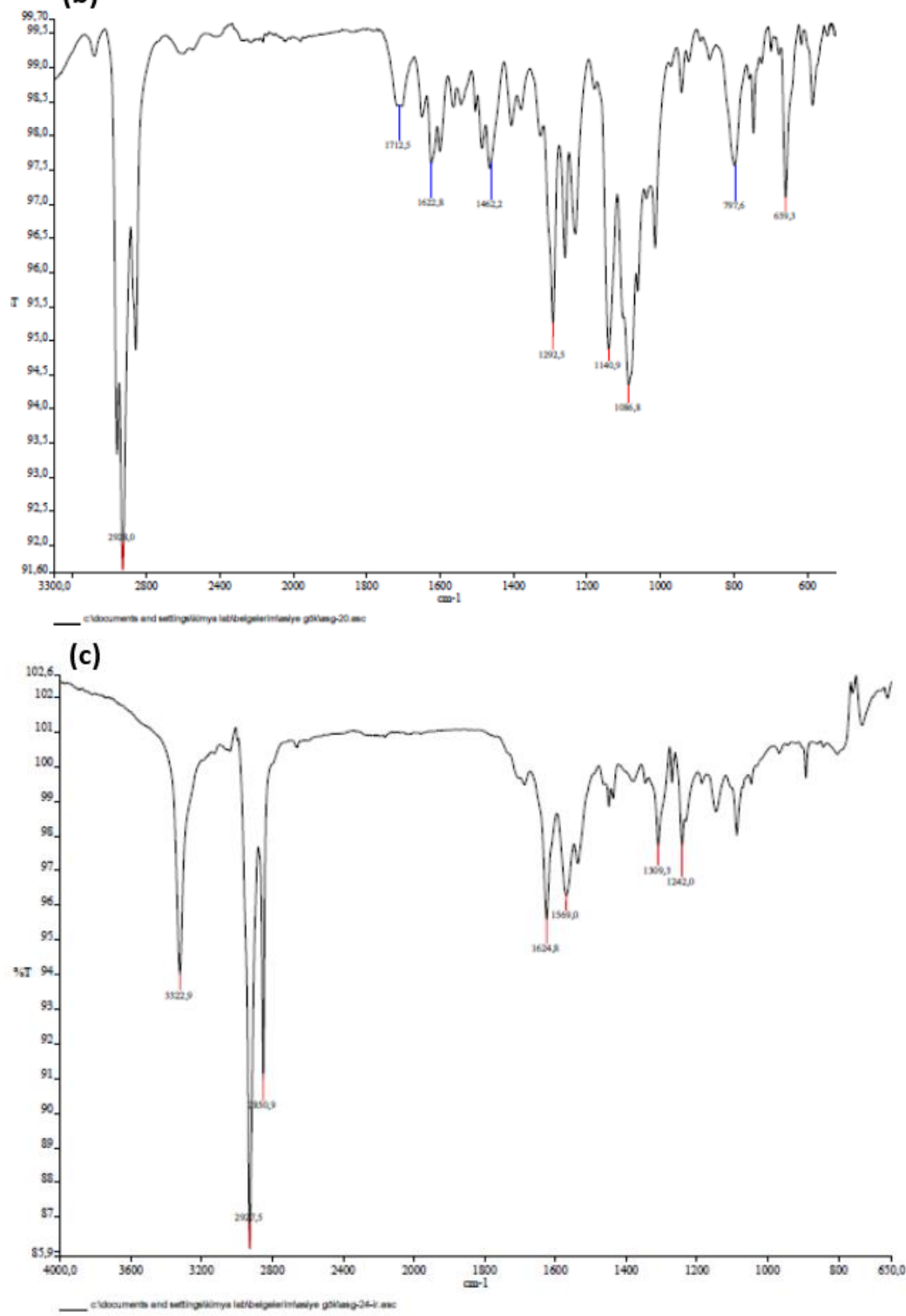
(d)

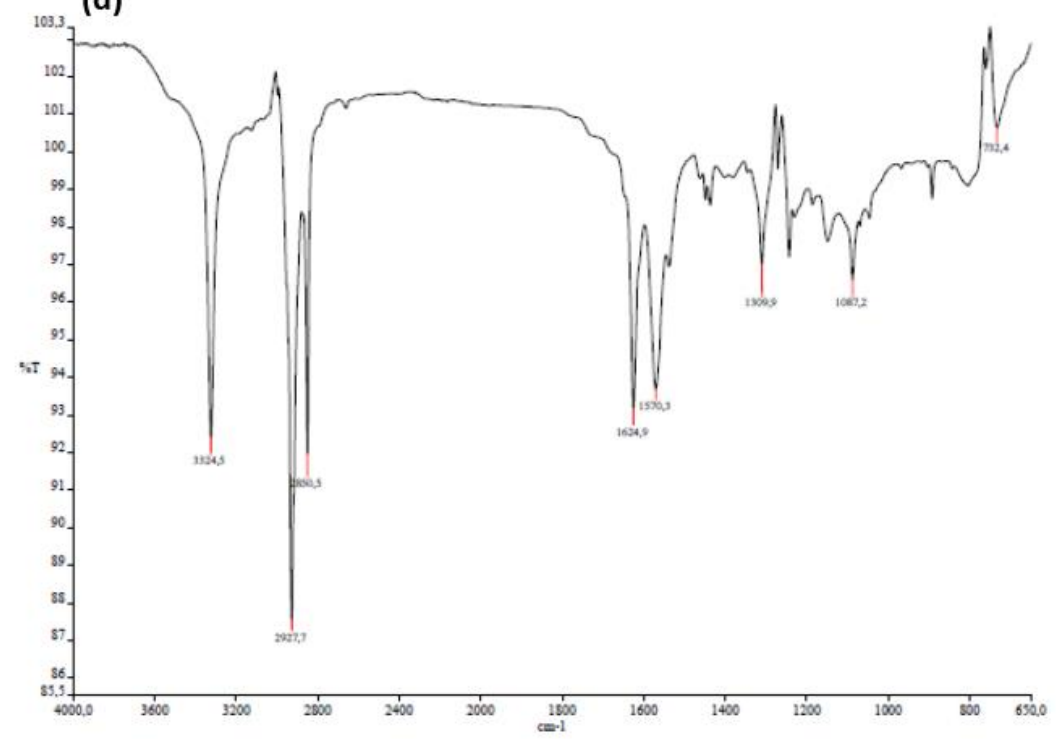

Figure S1. FT-IR spectra of (a) synthesized monofunctionalized phthalocyanine complex, (b) ASG20, (c) REF1, (d) REF2.

(a)

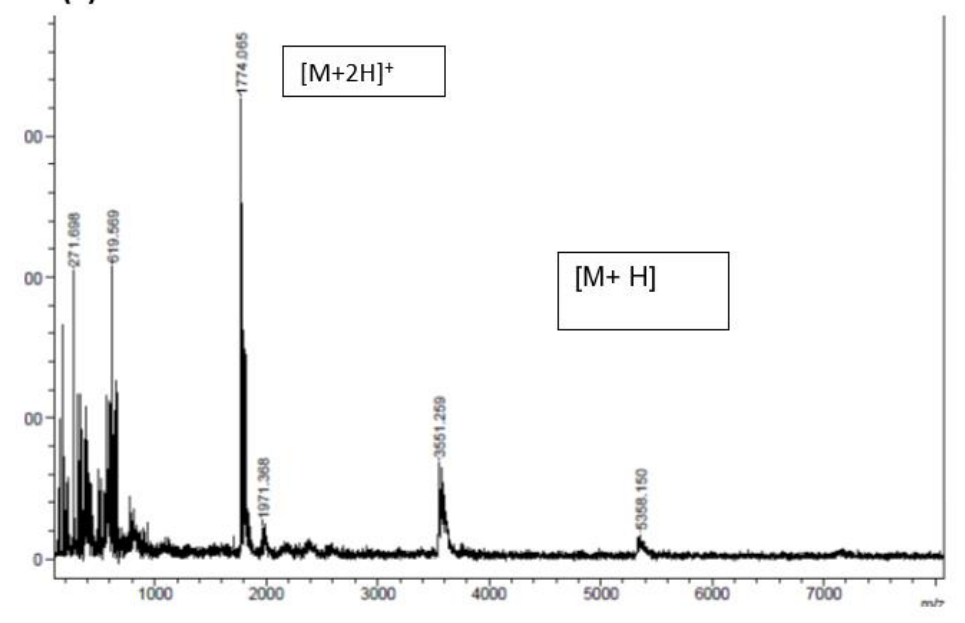

(b)

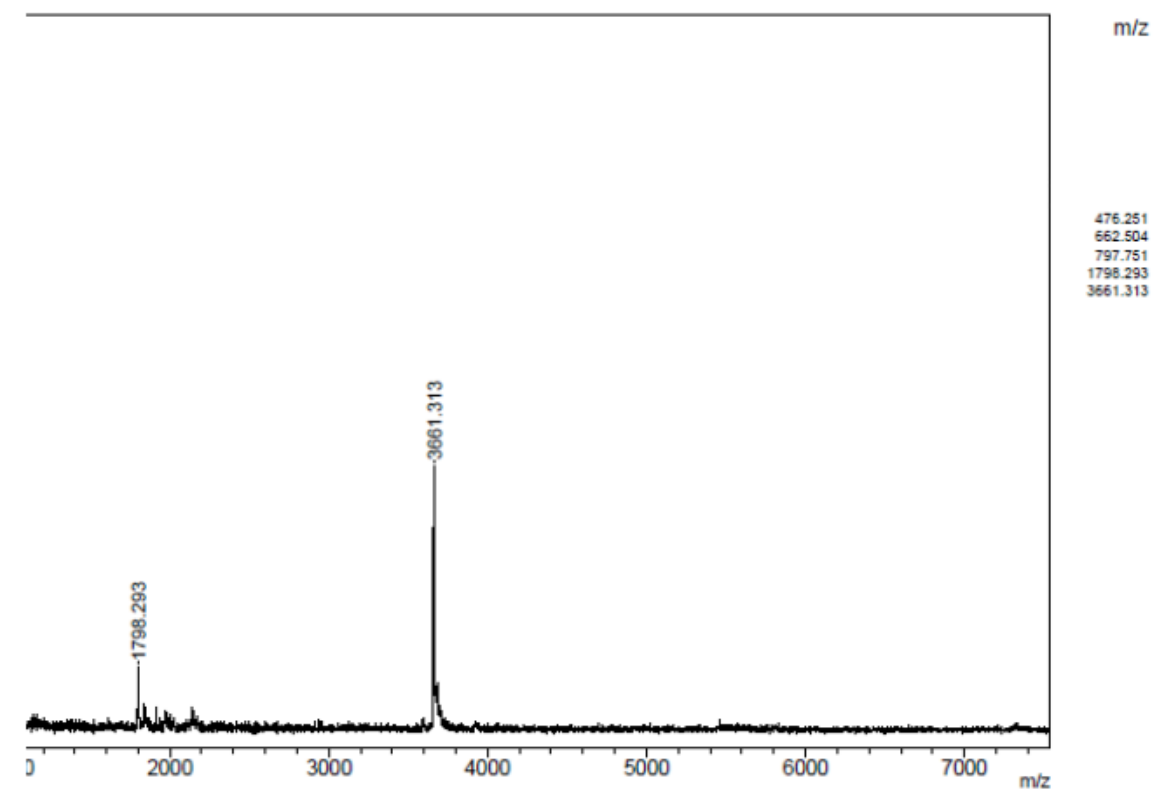


(c)

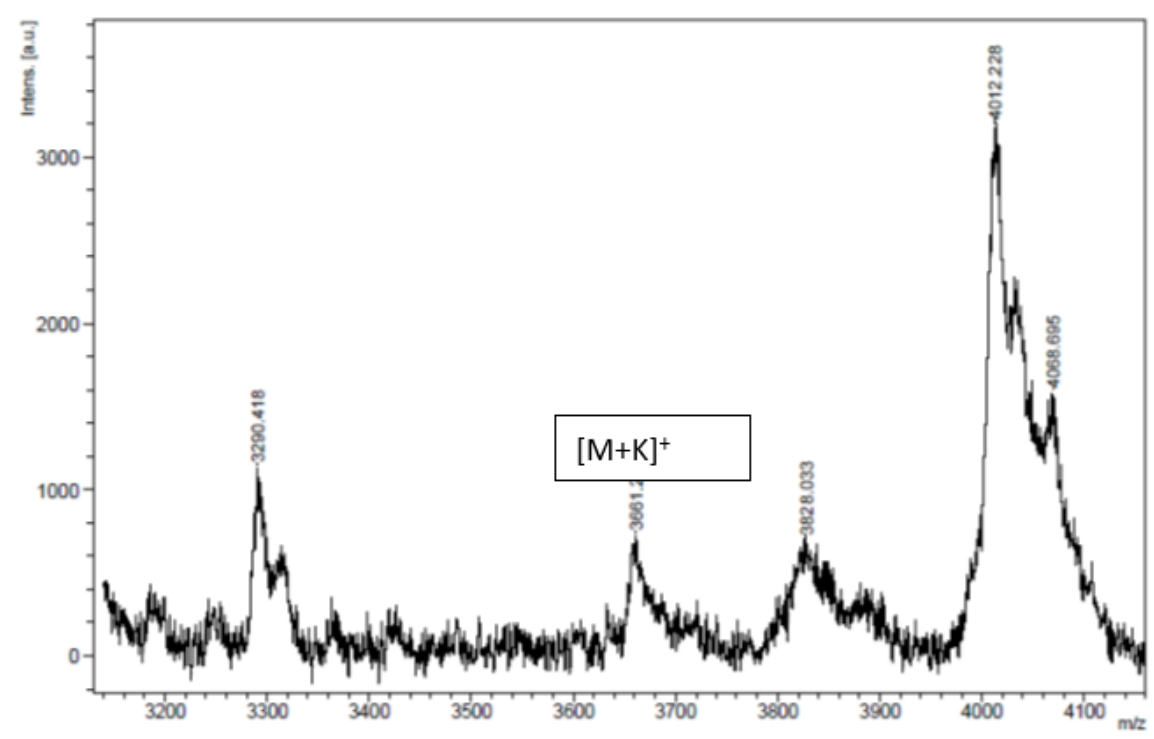

(d)

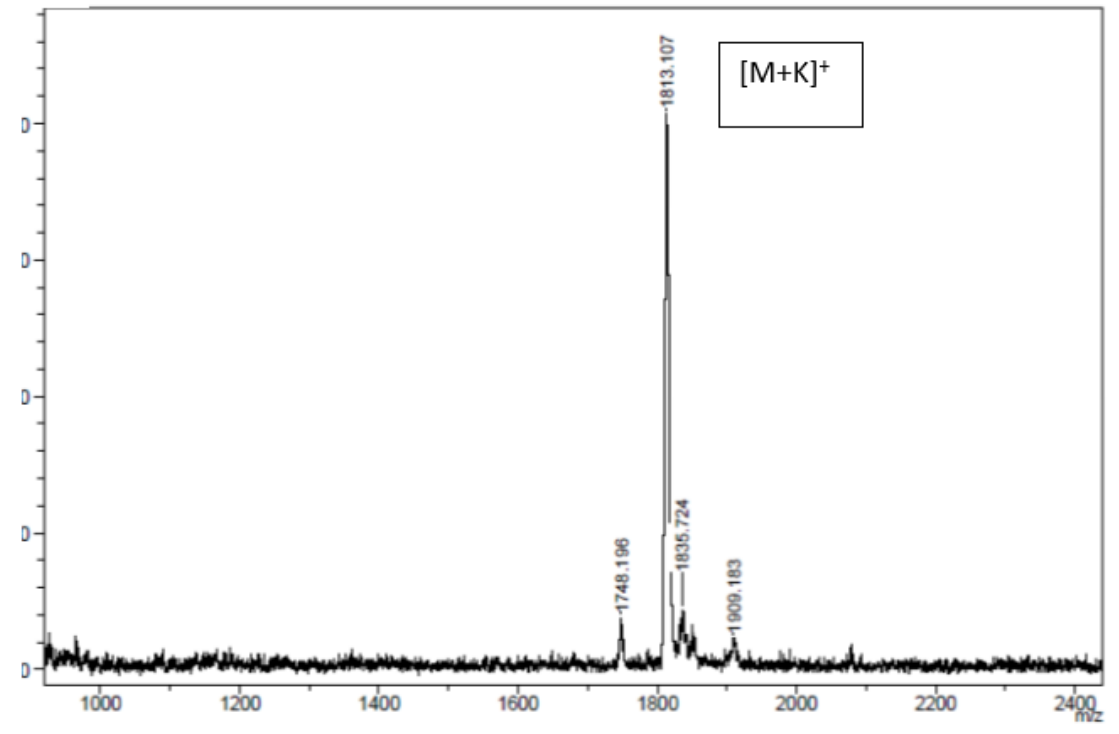

Figure S2. MS spectra of (a) synthesized monofunctionalized phthalocyanine complex, (b) ASG20, (c) REF1, (d) REF2. 